\title{
Establishment of a highly metastatic model with a newly isolated lung adenocarcinoma cell line
}

\author{
YONG-QI CUI", QIN GENG ${ }^{*}$, TAO YU, FANG-LIN ZHANG, HE-CHUN LIN, \\ JING LI, MIAO-XIN ZHU, LEI LIU, MING YAO and MING-XIA YAN \\ State Key Laboratory of Oncogenes and Related Genes, Shanghai Cancer Institute, Renji Hospital, \\ Shanghai Jiao Tong University School of Medicine, Shanghai 200032, P.R. China
}

Received April 13, 2015; Accepted May 18, 2015

DOI: 10.3892/ijo.2015.3065

\begin{abstract}
Lung cancer is the leading cause of malignancyrelated death worldwide, and metastasis always results in a poor prognosis. However, therapeutic progress is hampered by a deficiency of appropriate pre-clinical metastatic models. To bridge this experimental gap, we developed an in vivo metastatic model via subcutaneous (s.c.) injection. The original cell line (XL-2) adopted in this model was newly isolated from the ascites of a patient with extensive metastases of lung adenocarcinoma, thereby avoiding any alteration of its initial molecular biology features from artificial serial cultivation. After comprehensive phenotypical and histological analysis, it was identified as a lung adenocarcinoma cell line. Additionally, the drug test showed that XL-2 cell line was sensitive to docetaxel, and resistant to doxorubicin, indicating it might serve as a cell line model of drug resistance for identifying mechanisms of tumors resistant to doxorubicin. Through this s.c. model, we further obtained a highly metastatic cell line (designated XL-2sci). The metastatic rate of mice in XL-2 group was 3/10, in contrast to the rate of $9 / 10$ in XL-2sci group. Optical imaging, micro-computed tomography (micro-CT) scanning and Transwell assays were further applied to identify the enhanced metastatic capacity of Xl-2sci cells both in vivo and in vitro. Compared with XL-2 cells, ITRAQ labeled proteomics profiling study showed that some tumor metastasisassociated proteins were upregulated in XL-2sci cells, which also indicated the reliability of our model. Proliferation ability of XL-2 and XL-2sci were also evaluated. Results showed that
\end{abstract}

Correspondence to: Prof. Ming Yao or Dr Ming-Xia Yan, State Key Laboratory of Oncogenes and Related Genes, Shanghai Cancer Institute, Renji Hospital, Shanghai Jiao Tong University School of Medicine, No. 25/Ln 2200 Xietu Road, Shanghai 200032, P.R. China E-mail: myao@shsci.org

E-mail: mingxia_yan@126.com

*Contributed equally

Key words: highly metastatic model, lung cancer, metastatic ability, micro-CT, primary lung adenocarcinoma cell line highly metastatic XL-2sci possessed a decreased proliferation capacity versus XL-2, which demonstrated that its increased metastatic activity was not facilitated by a faster growth rate. In conclusion, we successfully developed an in vivo metastatic model using a newly established lung adenocarcinoma cell line, which will be beneficial to further investigations of lung cancer metastasis and to the development of anti-metastasis drugs.

\section{Introduction}

Lung cancer is currently considered the leading cause of malignancy-related death worldwide $(1,2)$ with a 5-year survival rate of $\sim 15 \%$ (3). Metastasis is one of the most devastating characteristics of cancer, which leads to almost $90 \%$ of all lung cancer deaths $(1,2)$. Although important advances have been made in understanding the pathogenesis and treatment of primary malignancy, little progress has been made in treating metastasis. Exploring the still undiscovered mechanisms of it will improve diagnosis and treatment methods. In this process, pivotal importance is attached to developing metastatic models because they can aid us in illustrating the underlying biological features of metastasis in more detail.

An ideal lung cancer metastatic model should not only mimic all aspects of tumor progression but should also be generally practical, stable and optimal. Subcutaneous (s.c.) injection, which has been widely used in the development of most human tumor models $(4,5)$, was also considered as the most appropriate method for lung cancer in our study, because orthotopic implantation is prone to complications, and its rate of tumorigenicity and metastasis formation in vivo is always unstable (6). Furthermore, unlike breast cancer and melanoma, an orthotopic model for lung cancer is relatively unavailable due to the inaccessibility of the anatomical location. Compared with tail intravenous injection, s.c. injection can adequately mimic the metastases of cancer, because it recapitulates the early biological steps that a primary tumor must undergo to form a distant metastatic site $(7,8)$, such as detachment of tumor cells from the primary site, invasion into the surrounding tissue, lymphatic or blood vessels and intravasation. Therefore, s.c. injection can credibly mimic the selection and evolution of metastasis.

After having been artificially cultivated in vitro for a long time, tumor cells often have altered phenotypes and genotypes, 
no longer maintaining the initial molecular characteristics and the heterogeneity of patient tumors $(9,10)$. Under such circumstances, s.c. xenograft models may present poor predictive power because of the inconsistencies between laboratory and clinical findings $(11,12)$. To circumvent these issues, new cell lines from patient-derived tumor samples are urgently needed. To fill this need, we established and characterized a new lung cancer cell line (designated XL-2) that was isolated from the ascites fluid of a Chinese patient with systemic lung cancer metastasis. Therefore, this cell line can reliably reproduce some important clinical features, such as metastatic behavior.

Through this in vivo metastatic model, we successfully obtained a highly metastatic subpopulation of XL-2 cell line (termed XL-2sci). ITRAQ label technology together with nano liquid chromatography-mass spectrometry (NanoLC-MS/MS) has proven to be efficient in protein analysis (13-15). Hence, the clinic-combined metastatic model and this technological means will increase the likeliness of discovering new metastasis-associated genes (16) and proteins (17) for identifying new antitumor targets.

\section{Materials and methods}

Cell lines and cell culture. The human lung cancer A549 cells were maintained in our laboratory and cultured in Dulbecco's modified Eagle's medium (DMEM, Invitrogen, Burlington, Ontario, Canada) supplemented with $10 \%$ fetal bovine serum (FBS) (Biowest, South America Origin), $100 \mathrm{U} / \mathrm{ml}$ penicillin (Sigma-Aldrich, St. Louis, MO, USA), and $100 \mu \mathrm{g} / \mathrm{ml}$ streptomycin (Sigma-Aldrich) at $37^{\circ} \mathrm{C}$ in a humidified air atmosphere containing $5 \% \mathrm{CO}_{2}$.

Patient materials. A 45-year-old Chinese male patient from Ruijin Hospital (Shanghai, China) was diagnosed with adenocarcinoma of the right lung. Despite undergoing a right upper lobe lobectomy, he still suffered from widespread metastases at one year following the operation. The right adrenal gland, both kidneys, bilateral lungs, retroperitoneal lymph nodes besides the liver were all involved in the metastasis progression. The patient's clinical situation continued to deteriorate, and predominant ascites was the concomitant symptom. Written informed consent for the scientific purpose of ascites specimen was obtained from him at the time of surgery, according to an established protocol approved by the Human Ethic Committee of Ruijin Hospital. All procedures adhered to the generally accepted guidelines for utilization of human materials.

Isolation of primary cell line from ascites. Approximately $60 \mathrm{ml}$ of ascites fluid was collected and immediately centrifuged at $1,500 \mathrm{x} \mathrm{g}$ for $5 \mathrm{~min}$. The upper supernatant was discarded and the remaining sediment washed with phosphate-buffered saline (PBS, Sangon Biotech, Shanghai, China) at 1,500 x g for $5 \mathrm{~min}$; the deposit was then resuspended in fresh PBS. Subsequently, density gradient centrifugation was performed using Percoll (Biodee Biotechnology, Beijing, China) to isolate the cells as previously described $(18,19)$ with slight modifications. The cell suspension was processed using a 60 and $40 \%$ Percoll gradient (1:1:1 volume ratio) at 3,000 x $\mathrm{g}$ for $30 \mathrm{~min}$ at room temperature. The cream-colored layer at the interface of the two Percoll gradients was collected and washed with PBS. After centrifugation at $1,500 \mathrm{x} g$ for $5 \mathrm{~min}$, the cell pellets were resuspended with DMEM, containing 10\% FBS, $100 \mathrm{U} / \mathrm{ml}$ penicillin and $100 \mu \mathrm{g} / \mathrm{ml}$ streptomycin; then incubated them at $37^{\circ} \mathrm{C}$ in a humidified atmosphere of $5 \% \mathrm{CO}_{2}$. Several days later, the bottom of the cell culture flask began to fill with numerous cells. Once the mixed cells reached confluence of $\sim 80 \%$, differential trypsinization was used to minimize the fibroblasts and mesothelial cells. Finally, a pure cancer cell line named XL-2 by our laboratory was harvested. Aliquots of cells in low passages were regularly stored in liquid nitrogen. Some others were further passaged for future study.

Morphological characteristics. For light microscopy, the morphology of XL-2 cells was observed using phase-contrast microscopy in bright fields as $80 \%$ confluent cultures (Olympus, Tokyo, Japan).

Determination of chromosome numbers. For chromosome preparation, XL-2 and XL-2sci cells were seeded in a $75-\mathrm{cm}^{2}$ culture flask (Corning, Lowell, MA, USA). The cells at $70 \%$ confluence were treated with colchicine $(0.2 \mu \mathrm{g} / \mathrm{ml})$ (Biodee Biotechnology) for $2 \mathrm{~h}$ before harvesting. After centrifugation, $75 \mathrm{mM}$ KCL hypotonic solution was added to the incubated cell pellets at a concentration of $1 \times 10^{4}$ cells $/ \mathrm{ml}$ for $25 \mathrm{~min}$ at $37^{\circ} \mathrm{C}$, prior to fixation with methanol/glacial acetic acid (3:1) following routine methods (20). The cell suspension was then dropped onto ice-cold slides and stained with Giemsa solution. Approximately 50 mitotic figures per cell were randomly analyzed and recorded.

Immunofluorescence. Immunofluorescence was performed to detect the expression of pan-cytokeratin (21-23) to identify the epithelial origin of XL-2. Because surfactant protein C (SP-C) is considered a marker of mature type II alveolar epithelial cells (AEC-II) (24-27), immunofluorescence was also used to evaluate its expression level. Cells were cultured on glass coverslips for $18-20 \mathrm{~h}$, fixed with $4 \%$ paraformaldehyde for $30 \mathrm{~min}$, and permeabilized in $0.25 \%$ Triton X-100 for 15 min. After blocking with immunostaining blocking buffer (Beyotime, Jiangsu, China), cells were subsequently incubated with the primary antibodies: rabbit polyclonal anti-SP-C (1:150, sc-13979; Santa Cruz Biotechnology, Santa Cruz, CA, USA) and anti-pan-cytokeratin (1:100, sc-15367; Santa Cruz Biotechnology) overnight at $4^{\circ} \mathrm{C}$. Slides were then incubated with a mixture of FITC-labeled goat anti-rabbit IgG (1:100, Sigma) and Alexa-Fluor-labeled chicken anti-rabbit IgG $\left(1: 100\right.$, Invitrogen) at $37^{\circ} \mathrm{C}$ for $1 \mathrm{~h}$. Finally, they were incubated with DAPI (1:200, Invitrogen) for $2 \mathrm{~min}$. Slides were viewed with a Fluoview FV1000 microscope (Olympus).

Western blot analysis. An equal amount of protein samples extracted from XL-2 and A549 (positive control) cells was separated using 15\% SDS-PAGE gels. Following electrophoresis, the proteins were transferred onto PVDF filter membranes (Millipore, Billerica, MA, USA). After blocking with $5 \%(\mathrm{w} / \mathrm{v})$ non-fat dry milk for $1.5 \mathrm{~h}$ at room temperature, the membrane was incubated with rabbit polyclonal anti-SP-C (1:400) antibody overnight at $4^{\circ} \mathrm{C}$. HRP-conjugated anti-rabbit IgG (1:4,000, Sigma-Aldrich) was used as a secondary 
antibody for a 2-h incubation. A 10-min PBST wash was conducted three times after each antibody incubation step. Subsequent visualization was performed using SuperSignal West Femto Maximun Sensitivity Substrate (Thermo Fisher Scientific, Waltham, MA, USA) and the loading control was $\beta$-actin (1:30,000, Sigma-Aldrich).

Animal experiments. Athymic male BALB/c-nu/nu mice, 6-8 weeks of age at experiments were provided by Shanghai Cancer Institute and maintained under specific pathogenfree (SPF) conditions. Housing and all procedures involving animals were performed in strict compliance with protocols approved by the Shanghai Medical Experimental Animal Care Commission at Shanghai Jiaotong University [approval ID SYXK (S) 2012-0001].

The tumorigenicity assay for XL-2 cell line was conducted as previously described (28). Ten nude mice were used for the s.c. route of inoculation. A total of $2 \times 10^{6}$ XL-2 cells mixed with $0.2 \mathrm{ml}$ saline were injected into the right upper flank of each mouse, and tumor growth was monitored regularly. When the s.c. tumors developed and reached $2 \mathrm{~cm}$ in largest dimension, they were removed, preserved in $10 \%$ buffered formalin and embedded in paraffin. Five non-sequential serial sections per animal were sampled for hematoxylin and eosin (H\&E) staining to evaluate tumor morphology and for subsequent immunohistochemistry (IHC) examination. Because A549 cell line was chosen as the positive control in IHC analysis, thus, slices derived from the A549 s.c. tumors were prepared in the same way as depicted above.

The model for testing drug-sensitivity of XL-2 was generated as previously reported (29). Briefly, thirty-six mice was randomly divided into two groups. The XL-2 group and A549 positive control group were respectively subcutaneously injected with $2 \times 10^{6}$ of XL-2 or A549 cells per mouse. When tumor volume reached $\sim 100 \mathrm{~mm}^{3}$, the corresponding group was equally divided into three subgroups $(n=6)$, and this day was designated as day 0 . The three subgroups were treated with three different formulations via intravenous injection: PBS (negative control), doxorubicin $(15 \mathrm{mg} / \mathrm{kg}$ ) (twice a week) and docetaxel (4 mg/kg) (once a week). Tumor size were regularly measured twice per week, and tumor volume $\left(\mathrm{mm}^{3}\right)$ was calculated using the formula: tumor volume $=0.5 \mathrm{x}$ length $\mathrm{x}$ width $^{2}\left(\mathrm{~mm}^{3}\right)$. When body weight of most of the mice in one subgroup declined by $20 \%$, the test of all the three subgroups were stopped, the mice were sacrificed, the tumors excised, and photographed.

To establish the metastatic model, a consecutive in vivo metastasis selection was carried out using XL-2 cell line via s.c. injection as previously described $(30,31)$. Briefly, XL-2 cells were injected subcutaneously into the mice, and primary tumors were excised 4 weeks later to improve the life-span of each mouse, and for checking the appearance of spontaneous lung metastasis. When the mice became moribund, macroscopic metastatic lesions were removed and implanted into the s.c. region of new recipient mice. Then the new flank-grown tumor was dissected to initiate the daughter cells. When a certain number of cells were present, they were re-injected subcutaneously into another recipient for the next round. This procedure was repeated three times. At the fourth and fifth rounds of selection, cells were generated directly from the isolated pulmonary nodules. Nodules were finely minced and then seeded in tissue culture dishes to generate cells. Routinely, primary tumors were no longer needed to be excised during the last two rounds for the shortened metastasis time in this stage.

For comparison of the primary tumor growth and spontaneous metastatic ability of XL-2 and XL-2sci cells, twenty mice were randomly divided equally into two groups. Both cell lines were implanted into the mice as described above. Tumor size was measured, and tumor volume was calculated. Nine weeks post-implantation, all individuals in these two parallel groups were euthanized. Liver, spleen and lung were all harvested at necropsy and processed according to the standard protocol for $\mathrm{H} \& \mathrm{E}$ staining to analyze the presence of metastases.

IHC. Sections from primary s.c. tumors of XL-2 were stained with pan-cytokeratin antibody (1:150) to confirm its epithelial origin. The following antibodies were used to identify the lung adenocarcinoma characteristics: thyroid transcription factor-1 (TTF-1) (1:150, sc-13040; Santa Cruz Biotechnology) and carcinoembryonic antigen (CEA) (1:100, 60053-1-Ig; Santa Cruz Biotechnology). All procedures were performed according to the manufacturer's protocols (Polymer HRP Detection System, Polink-2 plus, ZSGB-BIO, Beijing, China). Results were photographed and observed with a full-automatic slide scanning system (Leica, Solms, Germany).

Cells transduction. The GFP-Luc lentiviral vector was constructed by recombining the plasmid eGFP-2A-CBGr99 that encodes the GFP-Luc fusion gene (donated by Professor G.J. Hammerling) and a pWPXL vector (Addgene). Following the instructions described by Addgene (http://www.addgene. org), the XL-2 and XL-2sci cells were transfected with the recombinant vector expressing the fusion protein of GFP-Luc. Cell sorting (Epics Altra, Beckman Coulter) was further introduced to purify the stable transfectants expressing high levels of EGFP, and then the isolated cells were amplified by conventional culture methods.

Luciferase imaging and GFP imaging. A Berthold LB983 NC320 NightOwl System (Berthold, Bad Wildbad, Germany) was used in the s.c. xenografts model to monitor the primary and metastatic tumor growth of XL-2 and XL-2sci cells. All these procedures were conducted as previously described $(32,33)$. For in vivo bioluminescence imaging (in vivo BLI), the animals were given D-luciferin $(150 \mathrm{mg} / \mathrm{kg}$ body weight in PBS) (Promega, San Luis Obispo, CA, USA) by intraperitoneal injection and anesthetized with $1 \%$ pentobarbital sodium (10 ml/kg body weight) (Sigma-Aldrich). Imaging was completed $15 \mathrm{~min}$ after the injection. In monitoring pulmonary lesions, mice were euthanized, and their lungs were excised because signals from the s.c. tumor would disturb the observation. Ex vivo biofluorescence imaging (ex vivo $\mathrm{BFI}$ ) was adopted in this stage. The exposure time was 20 and $5 \mathrm{sec}$, respectively, for in vivo BLI and ex vivo BFI.

Micro-computed tomography (micro-CT) scanning. To provide three-dimensional non-destructive detection of the pulmonary lesions, micro-CT (Skyscan1076, Kontich, Belgium) was performed with the following parameters: 
$50 \mathrm{kV}, 200 \mu \mathrm{A}, 130$-ms exposure, 0.7 degree at angle of increment and 360 views. A normal mouse was also scanned as a negative control. The mice were anesthetized with $1 \%$ pentobarbital sodium $(10 \mathrm{ml} / \mathrm{kg}$ body weight) prior to the scanning. After being placed on its back on the animal bed and banded across the chest area, each mouse was imaged. Images of the chest were reconstructed.

Migration and Matrigel invasion assays. Analyses assessing the migration and invasion of cells were performed in 24-well Transwell plates $(8-\mu \mathrm{m}$ pore size, Corning). For the invasion assay, we first prepared Matrigel-coated Transwell chambers. Subsequently, $1 \times 10^{5}$ cells were added into the upper chamber of each well. For the migration assay, the number of cells seeded into upper chamber lined with a non-coated membrane was $5 \times 10^{4}$. Cells for both assays were resuspended with serum-free culture medium. To induce cell invasion, $800 \mu \mathrm{l}$ of $10 \%$ FBS medium was added to the lower chambers. The incubation lasted $16 \mathrm{~h}$ for migration assays and $24 \mathrm{~h}$ for invasion assays. Cells that had moved to the basal surface of the chamber were fixed, stained with $0.1 \%$ crystal violet and imaged with a CKX41 microscope (Olympus). Images of ten random fields from three replicate wells were obtained. The number of cells were counted, and the differences were analyzed. Assays were conducted three independent times.

In vitro growth kinetics. For growth kinetics, subconfluent cells were seeded at 2,000 cells/well in 96-well plates (Corning). After being incubated for $24 \mathrm{~h}$, the cells were counted at a regular time every day for one week. A mixture of $10 \mu \mathrm{l}$ of CCK8 (Dojindo, Kumamoto, Japan) and $100 \mu 1$ of DMEM was added to each well, which were then incubated for $2 \mathrm{~h}$. Three corresponding wells were measured together, and the average number of cells were calculated based on the absorbance at $450 \mathrm{~nm}$ of the triplicate wells. The cell doubling time $\left(\mathrm{T}_{\mathrm{d}}\right)$ was calculated using the formula: $\mathrm{T}_{\mathrm{d}}=\mathrm{T} \times \lg 2 /\left(\lg \mathrm{N}_{\mathrm{t}}-\lg \mathrm{N}_{0}\right)$, where $\mathrm{N}_{0}$ represents the number of cells at the beginning, $\mathrm{N}_{\mathrm{t}}$ means the number of total living cells at the time of counting and $\mathrm{T}$ represents the culturing time at the counting. The experiments were independently repeated three times.

Cell cycle analysis. Both XL-2 and XL-2sci cells were fixed with $70 \%$ ethanol at $-20^{\circ} \mathrm{C}$ overnight. After fixation, cells were rinsed twice with PBS, and then stained according to the manufacturer's protocol (cell cycle detection kit, KeyGena FACSCalibur flow cytometer (BD Biosciences, San Jose, CA, USA). Results were processed using ModFit software (BD Biosciences). Every cell line was independently analyzed three times.

Soft agar colony formation assays. For the soft agar colony formation assay, we used a two-layer technique as described elsewhere (34) with some modifications, which included a base layer consisting of $1 \%$ agar (Sigma-Aldrich) $(0.25 \mathrm{ml} /$ well $)$ and a second layer containing XL-2 or XL-2sci cells (1,000 cells/well) with $0.6 \%$ agar in a $24-w e l l$ plate. The plate was subsequently cultured for 14 days at $37^{\circ} \mathrm{C}$ under $5 \% \mathrm{CO}_{2}$. Finally, colonies formed were observed using an Axioskop 2 microscope (Carl Zeiss, Oberkochen, Germany) and a DP70 Imaging system (Olympus). This experiment was independently performed three times.
ITRAQ labeled quantitative proteomics analysis of XL-2 and $X L$-2sci cells. To comprehensively compare the proteome profile of highly metastatic XL-2sci cells and its parental XL-2 cells, iTRAQ quantitative proteomics approach was introduced (17). The first step was to prepare proteins as previously described (17). Second, the iTRAQ 4-Plex reagents (Applied Biosystems, Foster City, CA, USA) were applied to label the samples. Cell lysates of XL-2 and XL-2sci cells were, respectively, labeled with iTR AQ labeling reagents 114 and 115 . Briefly, comparable amount of each lysate $(100 \mu \mathrm{g})$ go through reducing, alkylating, digestion, plus desalination. Then, peptides were separated by means of Agilent HPLC with a high PH RP column (Durashell, C18, $250 \mathrm{~mm}$ $\mathrm{x} 4.6 \mathrm{~mm}, 5 \mu \mathrm{m})$. All these procedures were conducted as previously reported by our lab (35). Third, a NanoLC system (NanoLC-2D Ultra, Eksigent) was introduced to separate fractions and Triple TOF 5600 mass spectrometer (AB SCIEX, USA) was used for analysis. ProteinPilot4.1 software (AB SCIEX), was used for identification and quantification of protein was performed via database searching. The difference of the protein expression levels was considered significant if iTRAQ ratio (115:114) was $>1.5$ or $<0.67$. Finally, CapitalBio MAS 3.0 Molecule Annotation System (CapitalBio Corp., Beijing, http://bioinfo.capitalbio.com/mas3/) was used in Gene Ontology (GO) analysis of the upregulated and downregulated proteins. The analysis was performed mainly in three aspects: cellular component (CC), biological processes (BP) and molecular functions (MF).

Statistical analysis. Quantitative variables were represented as the mean \pm SD and analyzed using Student's t-test. Qualitative variables were compared by $\chi^{2}$ test. The significance level was set at $<0.05$. All the analyses were performed with SPSS 19.0 software (IBM Corp., New York, NY, USA).

\section{Results}

Cell morphology and phenotyping. A new lung cancer cell line designated XL-2 was generated from ascites fluid. Cells were regularly certified as free of bacteria or mycoplasma contamination. Determining the morphology revealed that monolayer, polygonal, epithelial-like cells adhered tightly to the bottom of the cell culture flasks (Fig. 1A). The epithelial origin was confirmed by positive immunoreactivity for epithelial marker (pan-cytokeratin) in primary cells (Fig. 1B) and IHC analyses of the s.c. tumor slides (Fig. 1C). XL-2 cell line engrafted well and gave rise to growth in vivo. Tumorigenicity rate was $100 \%$ in ten mice (data not shown). H\&E staining of the primary s.c. tumor is shown in Fig. 1D.

Chromosomal instability. Chromosome structural and numerical aberrations are critical for the initiation of tumorigenesis (36) and are crucial features of cancer cells versus normal ones. We therefore performed a karyotype analysis of XL-2 cell line. As shown in Fig. 1E (lower panel), the 50 randomly selected cells in metaphase contained between 44 and 55 chromosomes, with 51 and 53 being the predominant numbers. Both gains and loss of chromosomes were frequent in this cell line (Fig. 1E, upper panel). der(1)(?::q11 $\rightarrow$ q11::qter) and $\operatorname{der}(14)(14$ pter $\rightarrow q 11.2:: 1 q 12 \rightarrow q$ ter $)$ were the two significant 
A

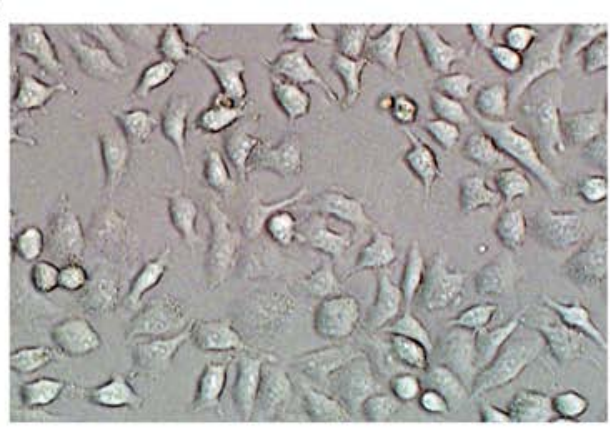

B
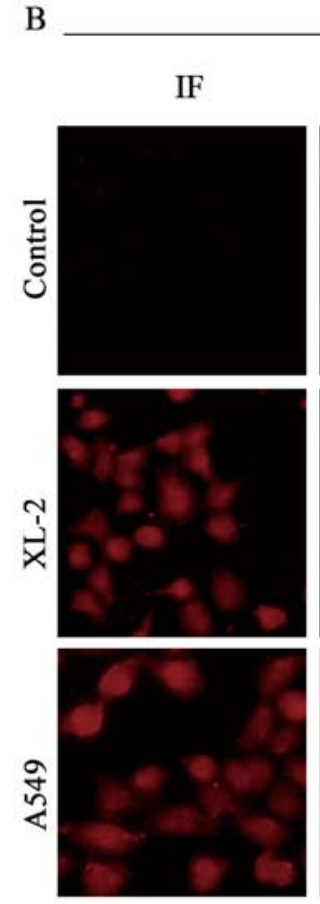

Pan-cytokeratin
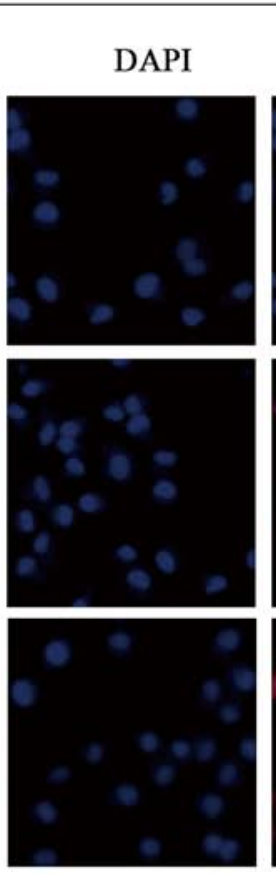
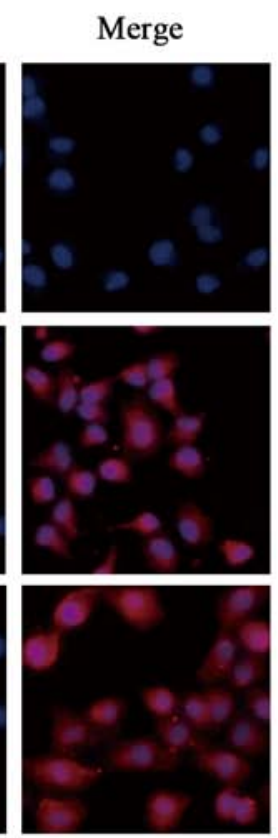

C

Pan-cytokeratin

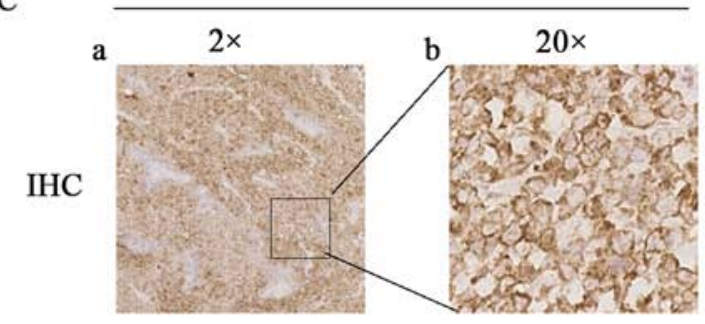

The primary tumor

D

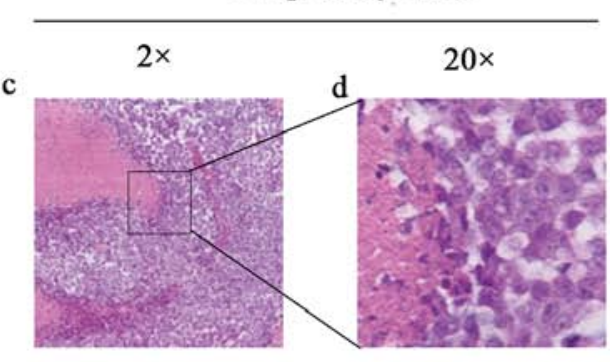

E

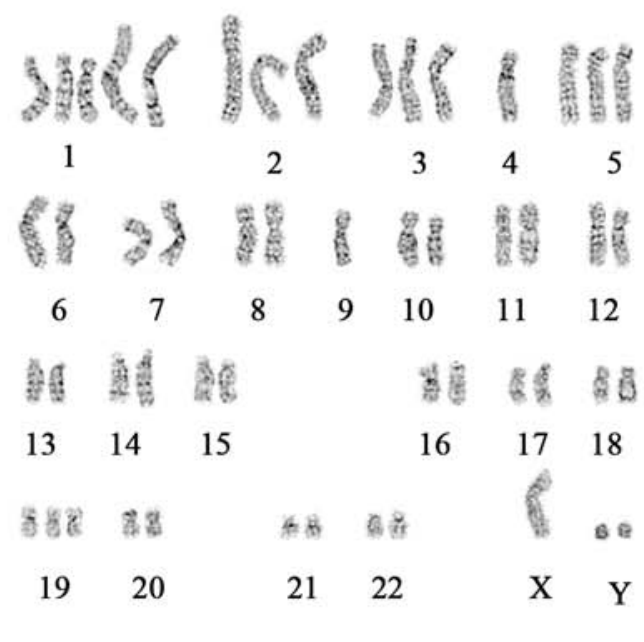

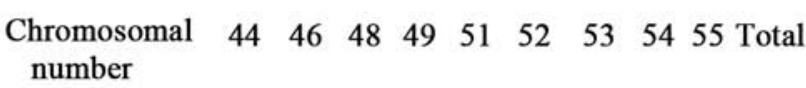

\begin{tabular}{llllllllllll}
\hline $\begin{array}{l}\text { Number of } \\
\text { cells }\end{array}$ & 1 & 1 & 8 & 5 & 13 & 4 & 16 & 1 & 1 & 50
\end{tabular}

Figure 1. Epithelial characteristics and chromosome analysis of the primary XL-2 cell line. (A) Confluent monolayer of primary cells illustrating typical epithelial polygonal morphology. Magnification, x200. (B) Immunofluorescence staining of pan-cytokeratin in XL-2 and A549 cells (positive control) demonstrating the epithelial origin of XL-2 cell line. A secondary antibody conjugated to Alexa-Fluor 568 (red fluorescent) was used to visualize the expression of pan-cytokeratin. Cell nuclei were stained with DAPI. Magnification, x200. (C) Representative IHC images of pan-cytokeratin expression in s.c. tumors. (D) H\&E staining of primary s.c. tumors. Original magnification (a and c), x2; (b and d), x20. (E) Numerous complex chromosomal rearrangements were observed in the XL-2 cell line. One representative karyotype showing the anomalies is exhibited (upper); the distribution of chromosome number counted randomly in 50 cells in metaphase (lower).

chromosomal translocations identified. In summary, XL-2 cell line displayed chromosomal instability and abnormal mitosis, which are hallmarks of cancer cells. Additionally, the distinction between the karyotype of XL-2 and that of a mouse, which includes 40 acrocentric chromosomes, confirmed its human cell origin at the same time.

The characteristics of lung adenocarcinoma. Because the clinicopathologic type of the tumor is lung adenocarcinoma, to determine whether XL-2 possesses the corresponding biological features, we first needed to prove that XL-2 is a lung cancer cell line. Immunofluorescence staining and western blotting were used to detect the expression of SP-C, which is produced by AEC-II. As shown in Fig. 2A, the cells were positive for SP-C by immunofluorescence detection. Western blot analysis (Fig. 2B) indicated that the XL-2 cells had a similar secretion level to that of the A549 cells (derived from AEC-II, a positive control). As CEA $(37,38)$ and TTf-1 (39-41) 
A
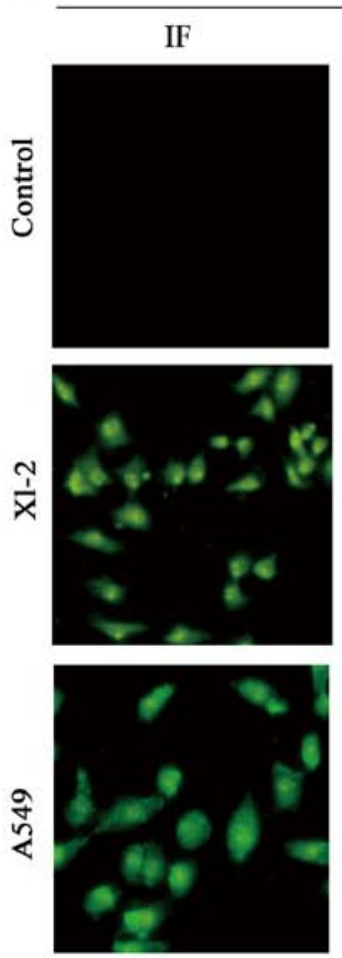

SP-C
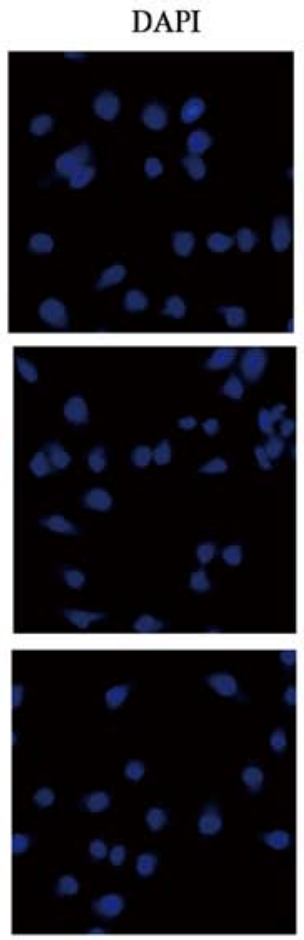

A549

B

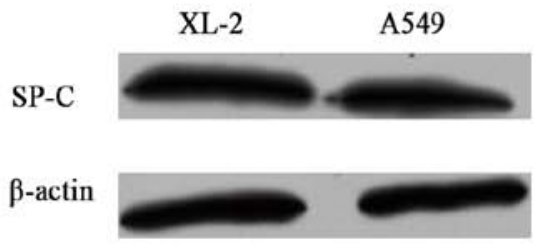

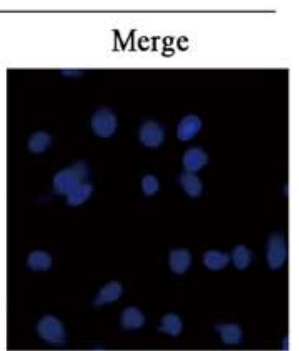
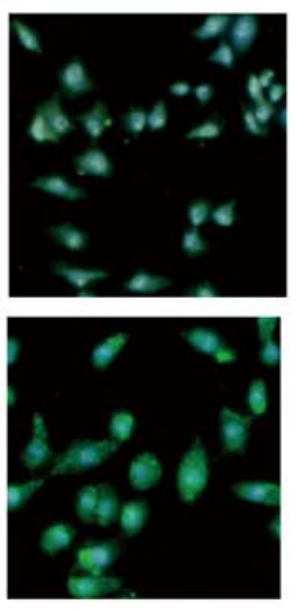

XL-2

$\mathrm{C}$
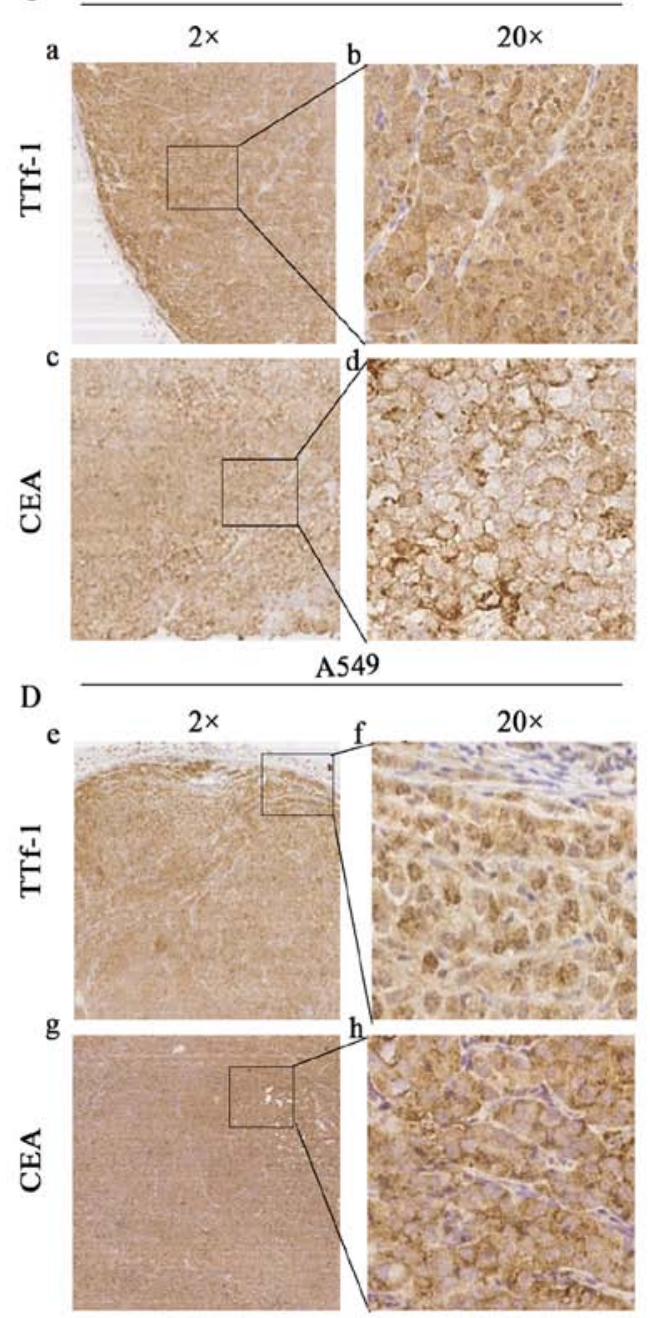

Figure 2. The alveolar type II epithelial cell origin and lung adenocarcinoma characteristics of XL-2 cell line. (A) Immunofluorescence staining of SP-C in XL-2 and A549 cells (positive control). FITC-labeled secondary antibody (green fluorescent) was used to observe the expression of SP-C. Cell nuclei were stained with DAPI. Magnification, x200. (B) Western blot analysis of SP-C in XL-2 and A549 cell lines. Protein lysates were resolved by 15\% SDS-PAGE. $\beta$-actin was used as a loading control. (C) Representative IHC images of the expression of TTf-1 and CEA in XL-2 s.c. tumors. (D) Representative IHC images of the expression of TTf-1 and CEA in the positive control A549 s.c. tumors. Original magnification (a, c ,e and g) x2; (b, d, f and h) x20.

are common markers used for identification of lung adenocarcinoma, we further performed IHC analysis of these two proteins using slides collected from the s.c. tumors of mice in the tumorigenicity assay. Samples derived from the A549 s.c. tumors was used as positive control. Remarkably, the tissues were positive for both CEA and TTf-1, with cytoplasmic and nuclear immunostaining, respectively (Fig. 2C), just as the control group (Fig. 2D). This immunoprofile was compatible with the features of adenocarcinoma. Thus, the XL-2 cell line showed consistency with the clinicopathologic diagnosis.

Drug susceptibility. Doxorubicin $(42,43)$ and docetaxel (44-47), which are commonly used as chemotherapy regimens for advanced non-small cell lung cancer (NSCLC), were introduced in the drug-sensitive of Xl-2 cells. As shown in Fig. 3A, in the three subgroups of XL-2 cells, docetaxel was apparently effective in inhibiting tumor volume, compared with the rapid tumor growth of PBS subgroup at day 21, and the difference was statistically significant (Fig. 4). Same conclusion could also be drawn in the A549 positive group, with docetaxel almost completely inhibiting the tumor growth (Fig. 3B). Because some tumors disappeared in A549 group, we can not depict its tumor growth curves. With regard to the sensitivity to doxorubicin, XL-2 and A549 cells exhibited different responses. In the subgroup of A549, the majority of s.c. tumors exhibited a smaller volume than the PBS subgroup, and the tumors of two mice even disappeared (Fig. 3B). However, the antitumor efficiency of doxorubicin in XL-2 subgroup was not so evident, and there was not a statistical difference between the tumor volume of doxorubicin subgroup and the PBS subgroup (Fig. 4).

Highly metastatic XL-2sci cell line obtained from in vivo selection. At the fifth round of screening, the lung metastases were most obvious, and we obtained a highly metastatic subline of XL-2 (designated XL-2sci). Additionally, we representatively present the data in the first, third and fifth rounds of selection to prove the escalating trend of the lung metastatic rate (Table I). 


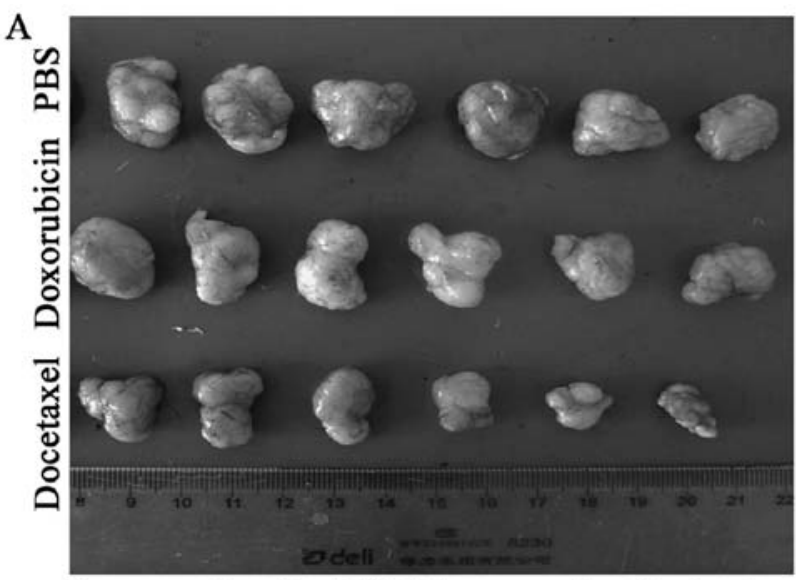

Images of excised Xl-2 tumors after the treatment

B

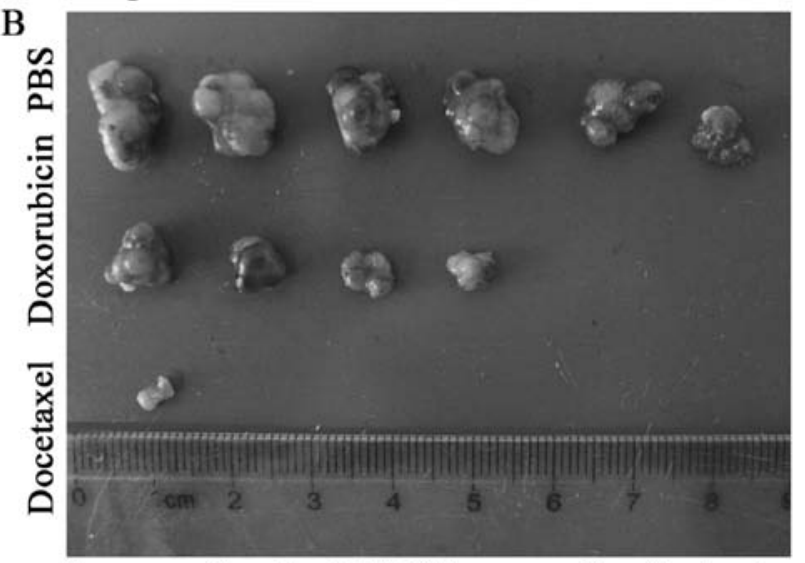

Images of excised A549 tumors after the treatment

Figure 3. Images of excised XL-2 and A549 tumors of different drug treatment strategies. (A) Images of excised XL-2 tumors after the mice had been, respectively, treated with PBS, doxorubicin and docetaxel. (B) Images of excised A549 tumors after the mice had been, respectively, treated with PBS, doxorubicin and docetaxel.

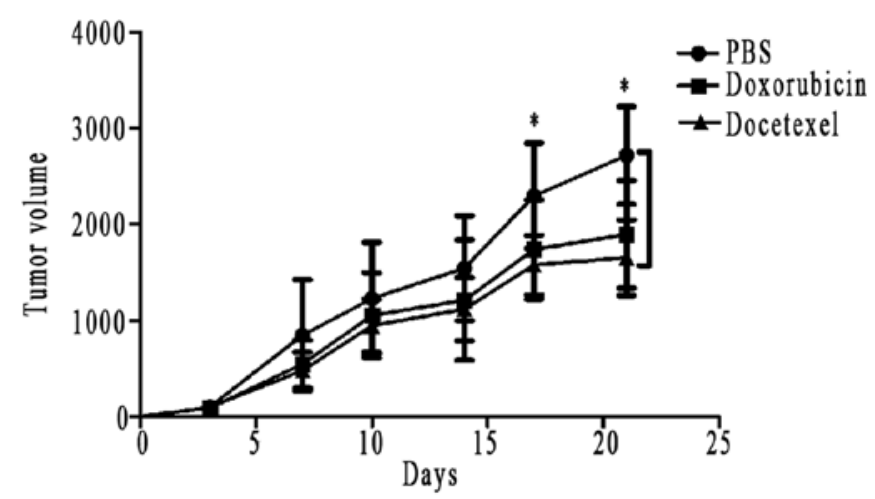

Figure 4. Tumor growth curves of XL-2 group after different treatment strategies. Tumor volume changes after treatment with different drug formulations in nude mice bearing XL-2 human lung cancer xenograft. The data are shown as mean $\pm \operatorname{SD}(n=6)$. ${ }^{*}$ There was statistical significance between the tumor volume of docetaxel subgroup and PBS subgroup at days 17 and 21. It is notable that there was no statistical significance between the tumor volume of doxorubicin subgroup and PBS subgroup.

Karyotype analysis of XL-2sci was also performed, and results showed that in the 50 randomly selected cells in metaphase, the number of chromosomes ranged from 45 to 58 , with
Table I. Lung metastatic rate and selection periods in the first, third and fifth round of in vivo metastasis selection.

\begin{tabular}{lcc}
\hline Round & Lung metastatic rate & Selection periods (days) \\
\hline First & $3 / 10$ & 99 \\
Third & $6 / 10$ & 78 \\
Fifth & $9 / 10$ & 63
\end{tabular}

${ }^{a}$ The number of mice with lung metastasis identified by pathological sections/the total number of mice; b the average time consumed for the appearance of the lung metastasis.

A

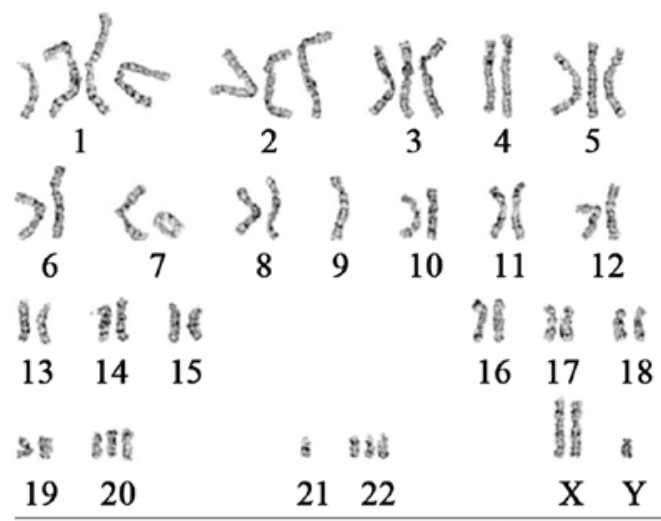

B

Chromosomal 454648495152535455565758 Total number

\begin{tabular}{llllllllllllll}
\hline $\begin{array}{l}\text { Number of } \\
\text { cells }\end{array}$ & 2 & 2 & 8 & 12 & 14 & 1 & 3 & 2 & 3 & 1 & 1 & 2 & 50 \\
\hline
\end{tabular}

Figure 5. Chromosome analysis of the XL-2sci cell line. (A) Numerous complex chromosomal rearrangements were observed in the XL-2sci cell line. A representative karyotype showing the marker chromosome and other anomalies is exhibited. (B) The distribution of chromosome number counted randomly in 50 cells in metaphase.

49 and 51 being the predominant numbers. The two chromosomal translocations identified in XL-2 cells were also observed in XL-2sci cells. However, der(9)(9pter $\rightarrow$ p11::1q11 $\rightarrow$ qter $)$ was the third translocation unique to this cell line. Furthermore, there was a marker chromosome in XL-2sci cells (data shown in Fig. 5).

Metastatic lesions were more apparent in mice injected with XL-2sci cells (Fig. 6A), which were further identified by histological analysis (Fig. 6B). Mice in XL-2sci group had significantly more pulmonary metastatic spots than those in XL-2 group $(\mathrm{P}<0.01)$ (Fig. 6C). The metastasis rates were 9/10 and $3 / 10(\mathrm{P}<0.05)$ in $\mathrm{XL}-2$ sci and $\mathrm{XL}-2$ tumor-bearing mice, respectively (Fig. 6D). In brief, the two cell lines differed in metastatic ability, with XL-2sci being superior to XL-2.

Comparison of the metastatic ability in vivo with optical imaging and micro-CT scanning. To provide a more intuitive 
A

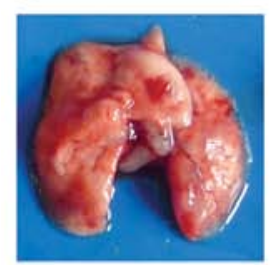

XL-2

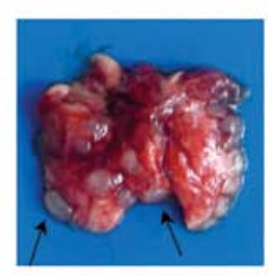

XL-2sci

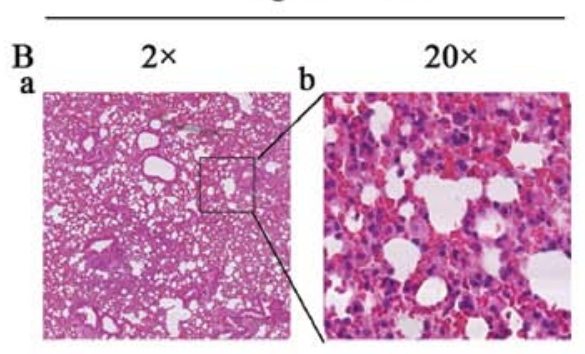

XL-2

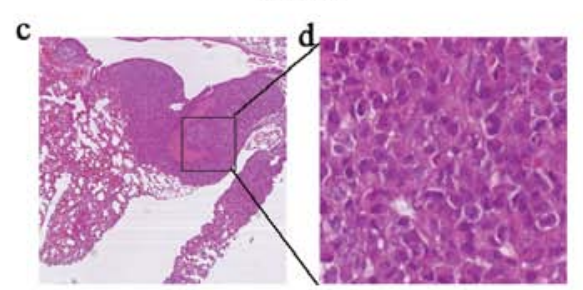

XL-2sci

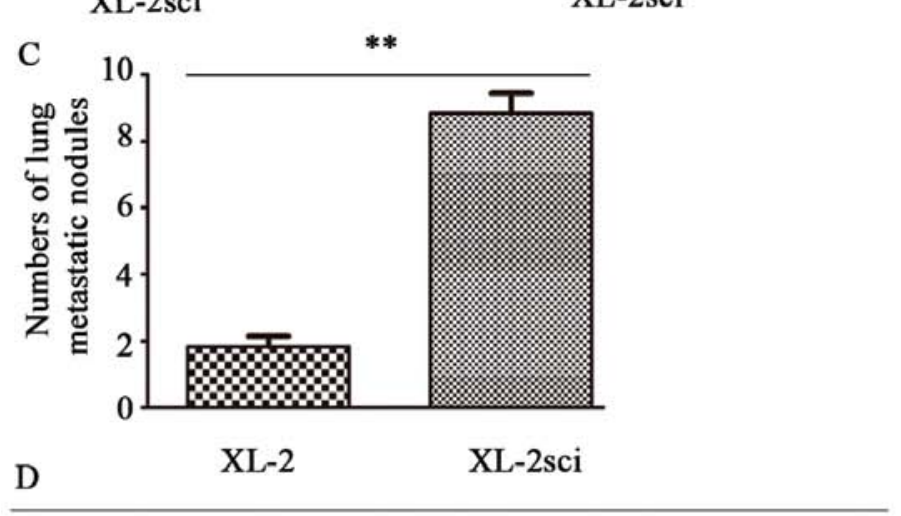

\begin{tabular}{lcl}
\hline & Lung metastasis & P value $(\chi 2$ test $)$ \\
\hline XL-2 & $3 / 10^{*}$ & \\
XL-2sci & $9 / 10$ & $P<0.05$
\end{tabular}

E

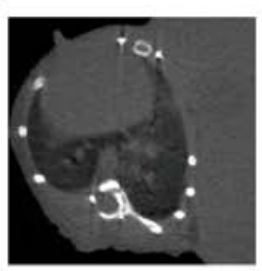

$\mathrm{XL}-2$

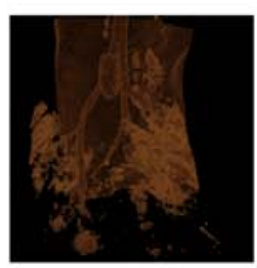

XL-2

F

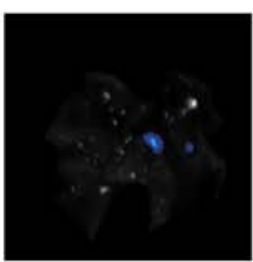

XL-2

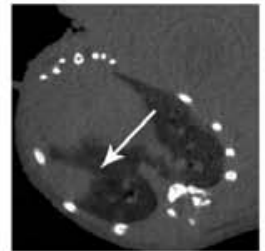

XL-2sci

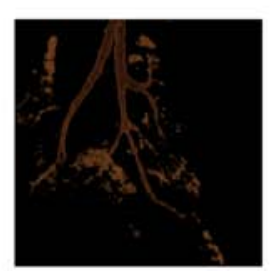

XL-2sci

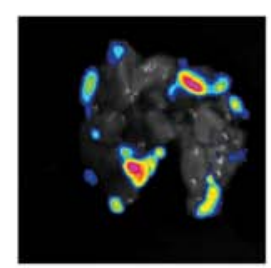

XL-2sci

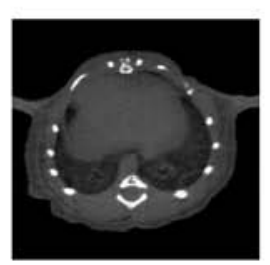

Negative control

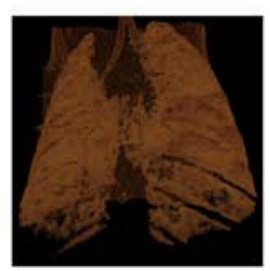

Negative control

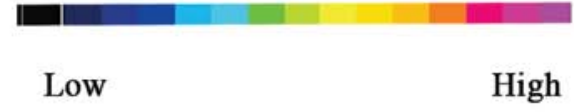

Figure 6. A new cell line (XL-2sci) with enhanced metastatic competence was acquired after five rounds of sequential in vivo selection. (A) Corresponding representative images of lungs from the XL-2 and XL-2sci groups. Compared to XL-2 group, massive metastatic nodules to the lungs emerged in the XL-2sci group nine weeks after s.c injection of tumor cells. (B) H\&E staining of lungs isolated from the mice. Microphotography showed that massive tumor cells replaced the lung tissues in the XL-2sci group. Magnification, (a and c) x2; (b and d) x20. (C) Quantification of microscopic nodules in the lungs in each group (XL-2 versus XL-2sci) $(n=10)$. (D) A table depicting the incidence of lung metastasis in the two groups. ${ }^{*} \mathrm{P}<0.05,{ }^{* *} \mathrm{P}<0.01$; arrows show the metastatic nodules. (E) Micro-CT scanning of lung tumors. Upper panel, axial transverse sections obtained from the mice revealed that recipients in XL-2sci group had more metastatic nodules. A normal mouse was also scanned as a negative control for more convenient observations. Tumors observed in the lungs are shown by arrows. We also observed in the images that the thorax of the mice had already deformed due to the compression of s.c. tumors. Lower panel, three-dimensional images of the lungs. Mice in XL-2 group also exhibited limited lung lesions, consistent with clinical features of the disease in the patient suffering from extensive metastasis. (F) Representative ex vivo BFI images of lungs harvested at the end of the experiment. The color scale indicates the photon flux emitted from the lungs of each xenografted mouse.

way to estimate the in vivo characteristics of these two cell lines, we subcutaneously injected GFP- and luciferase-labeled XL-2 and XL-2sci cells as described above, which permitted us to monitor tumor growth and metastasis non-invasively and semi-quantitatively. When mice displayed signs of being moribund ( 9 weeks later), lung metastases were monitored by in vivo BLI. However, the positive BLI signals from primary s.c. tumors were so strong that they interfered with the identification of pulmonary nodules. Micro-CT imaging was then introduced. As shown in Fig. 6E, obvious tumor nodules were noted in XL-2sci group. Changes in XL-2 group also appeared but were minor. Significant differences with regard to tumor burden were observed between the two groups. In the subsequent disposal, ex vivo BFI imaging was applied to the evaluation of pulmonary metastasis. A good accordance was demonstrated between ex vivo BFI and micro-CT data from the same time-point. As shown in Fig. 6F, light-emitting foci were mostly localized in the XL-2sci group because only a low level of photons was emitted from the recipients in the XL-2 group. In short, XL-2sci cells were more prone to metastasize in vivo.

Comparison of cellular migration and invasive capability in vitro. Considerable differences were observed in the 

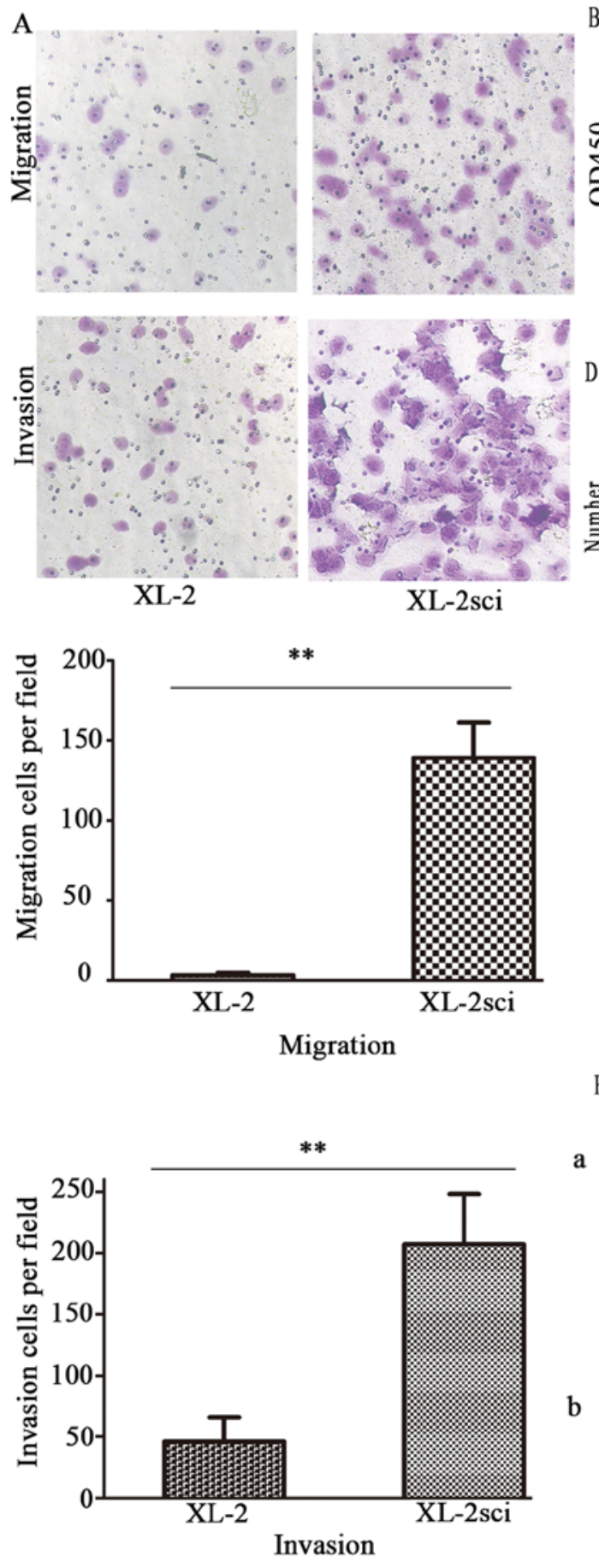

a
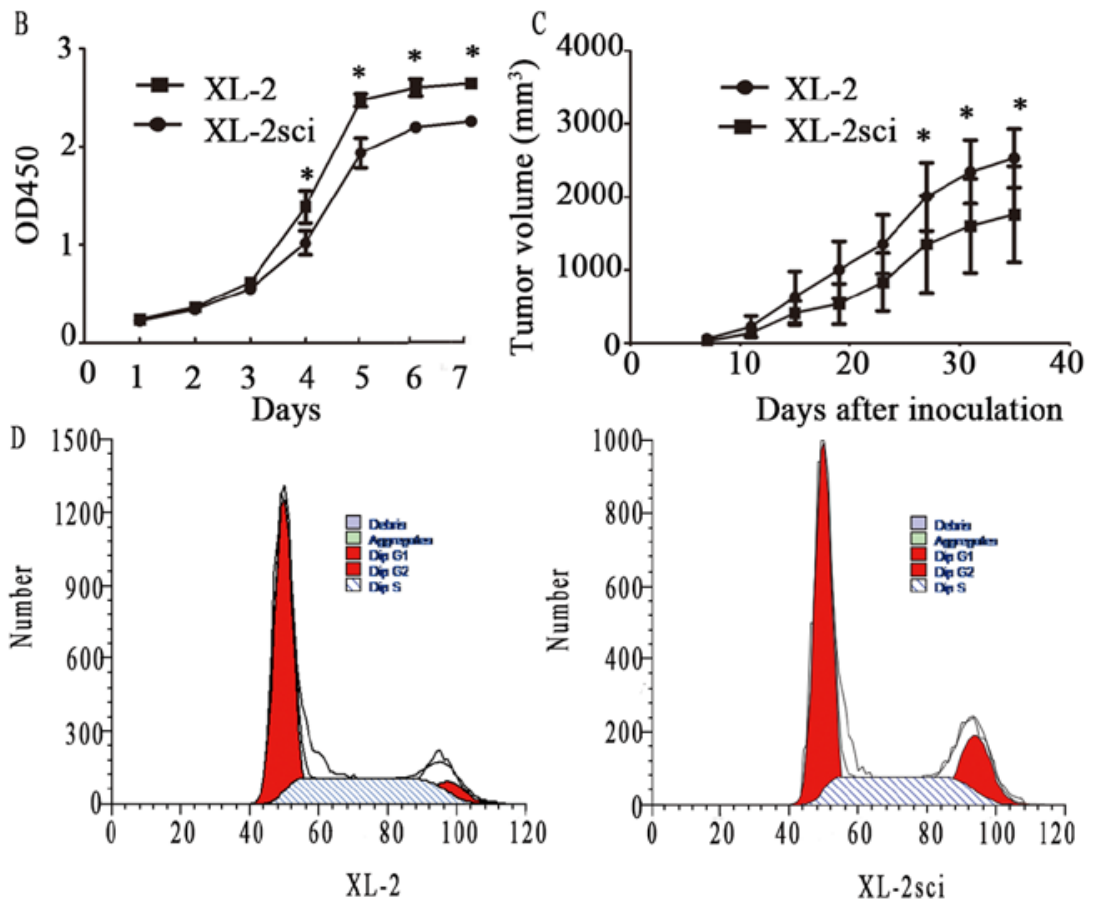

\begin{tabular}{cllc}
\hline & \multicolumn{3}{c}{ Cell cycle } \\
\cline { 2 - 4 } & $\mathrm{G} 1(\%)$ & $\mathrm{S}(\%)$ & $\mathrm{G} 2 / \mathrm{M}(\%)$ \\
\hline $\mathrm{XL}-2$ & $56.19 \pm 0.86$ & $35.28 \pm 0.0 .016$ & $8.54 \pm 0.016$ \\
$\mathrm{XL}-2 \mathrm{sci}$ & $53.07 \pm 2.76^{*}$ & $28.15 \pm 0.025^{* *}$ & $18.79 \pm 1.225^{* *}$ \\
\hline
\end{tabular}

E
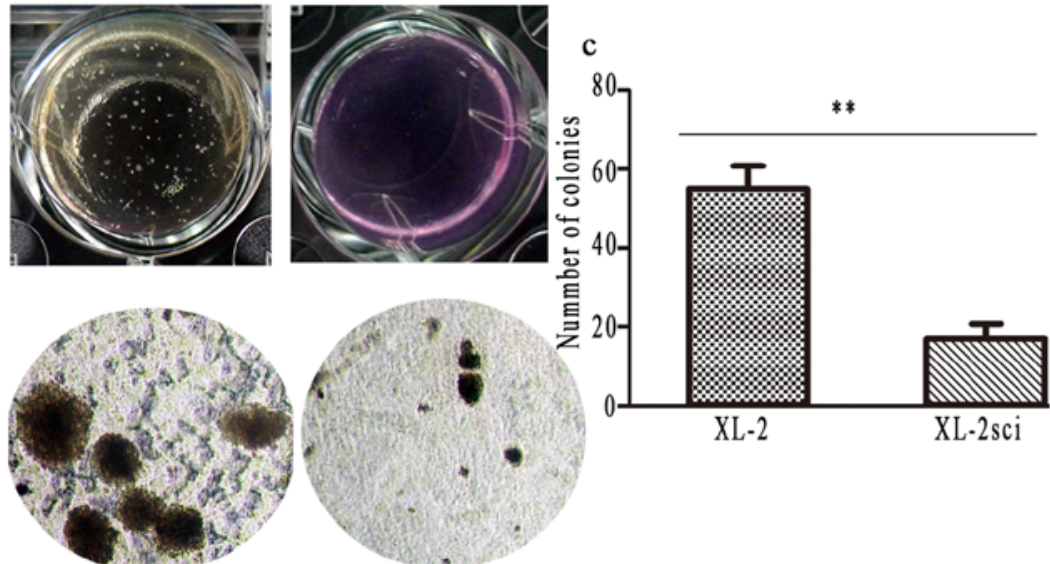

$\mathrm{XL}-2$

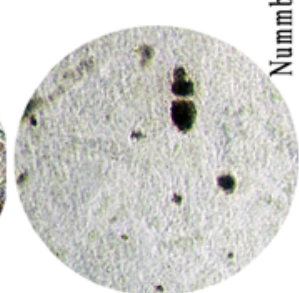

XL-2sci

Figure 7. The comparison of migration, invasive and proliferation potential. (A) Comparison of migration and invasive potential of XL-2 and XL-2sci cells. The phase-contrast images (upper panels) show that more XL-2sci cells penetrated through the underside of the inserts than did XL-2 cells in both migration and invasion assays (magnification, $x 100$ ). The lower panels show histograms of the quantification. The results are represented as the mean \pm SD from at least three independent experiments, ${ }^{* *} \mathrm{P}<0.01$. (B) In vitro growth curves of XL-2 and XL-2sci cells. Cells were seeded into the corresponding 96-well plates, after which cells were counted at the indicated times. Results are expressed as the mean $\pm \mathrm{SD} ;{ }^{*} \mathrm{P}<0.05$. (C) In vivo growth curve of XL-2 and XL-2sci cells. Cells (2.0x $10^{6}$ per mouse) were subcutaneously implanted into BALB/c-nu/nu mice, after which the tumor volume was measured every four days. The results are expressed as the mean $\pm \mathrm{SD},{ }^{*} \mathrm{P}<0.05$. (D) Cell cycle analysis. Upper panel, representative images of the cell cycle assays. Lower panel, a table depicting the results of the cell cycle assays. The percentage of XL-2sci cells in S phase was lower than that of XL-2 cells, ${ }^{*} \mathrm{P}<0.05,{ }^{* *} \mathrm{P}<0.01$. (E) Soft agar colony formation assay (clonogenic assay) of XL-2 and XL-2sci cells. (a) Large-scale image of the soft agar colony formation assay. (b) Representative image of the microscopic colonies. (c) Quantification of the colonies expressed as the mean $\pm \mathrm{SD} ;{ }^{* *} \mathrm{P}<0.01$.

migration and invasive properties of these two cell lines, as evaluated by in vitro Transwell migration and invasion assays (Fig. 7A). Regarding the invasive potential, significantly more
XL-2sci cells passed through the Matrigel than did XL-2 cells. The parallel migration assay yielded similar results. These data suggest that the XL-2sci cells are markedly more aggres- 
Table II. List of upregulated proteins.

\begin{tabular}{|c|c|c|c|c|c|}
\hline $\begin{array}{l}\text { Accession } \\
\text { no. }^{\text {a }}\end{array}$ & $\begin{array}{l}\text { Protein } \\
\text { name }\end{array}$ & $\begin{array}{l}\text { Unused score } \\
(\text { mean } \pm S D)^{b}\end{array}$ & $\begin{array}{c}\% \operatorname{cov}(95) \\
(\operatorname{mean} \pm \mathrm{SD})^{\mathrm{c}}\end{array}$ & $\begin{array}{l}\text { Peptides }(95 \%) \\
(\text { mean } \pm \text { SD })^{\mathrm{d}}\end{array}$ & $\begin{array}{l}\text { iTRAQ rate } \\
(\text { mean } \pm \text { SD })^{\mathrm{e}}\end{array}$ \\
\hline P00918 & CAH2 & $7.8 \pm 0.282842712$ & $28.45 \pm 8.697413409$ & $6 \pm 1$ & $2.49565 \pm 0.259578899$ \\
\hline P02787 & TRFE & $2.34 \pm 0.890954544$ & $12.5 \pm 0$ & $3 \pm 1$ & $1.9729 \pm 0.332481609$ \\
\hline P04083 & ANXA1 & $47.845 \pm 3.217335854$ & $65.6 \pm 2.828427125$ & $59 \pm 4$ & $1.933 \pm 0.088105505$ \\
\hline P05787 & $\mathrm{K} 2 \mathrm{C} 8$ & $83.885 \pm 4.207285348$ & $71.7 \pm 0.141421356$ & $75 \pm 4$ & $1.6534 \pm 0.096873629$ \\
\hline P09525 & ANXA4 & $18.435 \pm 8.195367594$ & $52.2 \pm 6.929646456$ & $12 \pm 4$ & $2.67675 \pm 0.485428805$ \\
\hline P10768 & ESTD & $7.16 \pm 1.060660172$ & $28.2 \pm 0.282842712$ & $6 \pm 1$ & $2.4864 \pm 1.081166268$ \\
\hline Q04446 & GLGB & $119.205 \pm 6.75286976$ & $74.55 \pm 1.060660172$ & $123 \pm 1$ & $1.7236 \pm 0.257245447$ \\
\hline Q16658 & FSCN1 & $19.53 \pm 1.824335495$ & $35.7 \pm 7.778174593$ & $14 \pm 0$ & $2.2537 \pm 0.205202388$ \\
\hline Q16719 & KYNU & $30.67 \pm 1.555634919$ & $47.95 \pm 2.757716447$ & $19 \pm 1$ & $1.83485 \pm 0.332693741$ \\
\hline Q32MZ4 & LRRF1 & $29.275 \pm 0.360624458$ & $46 \pm 0$ & $22 \pm 1$ & $1.89915 \pm 0.135976634$ \\
\hline Q92597 & NDRG1 & $17.18 \pm 1.187939392$ & $28.9 \pm 0.424264069$ & $10 \pm 0$ & $2.2508 \pm 0.747977553$ \\
\hline Q96FQ6 & S10AG & $4.02 \pm 0.028284271$ & $8.65 \pm 2.899137803$ & $2 \pm 0$ & $2.0106 \pm 0.222172951$ \\
\hline Q99584 & S10AD & $4.88 \pm 3.577960313$ & $42.7 \pm 0$ & $3 \pm 1$ & $3.37905 \pm 1.226335291$ \\
\hline Q9H2J7 & S6A15 & $3.365 \pm 1.859690835$ & $25 \pm 6.505382387$ & $3 \pm 1$ & $1.6524 \pm 0.053740115$ \\
\hline Q9H2J7 & S6A15 & $2.84 \pm 1.48492424$ & $8 \pm 1.272792206$ & $3 \pm 1$ & $1.91475 \pm 0.062296107$ \\
\hline B2WTI4 & B2WTI4 & $7.135 \pm 1.364716088$ & $23.55 \pm 1.626345597$ & $6 \pm 1$ & $1.60065 \pm 0.08336789$ \\
\hline E7EU05 & E7EU05 & $9.18 \pm 0.339411255$ & $21.25 \pm 2.61629509$ & $7 \pm 0$ & $3.11955 \pm 1.429699201$ \\
\hline G3V1S6 & G3V1S6 & $17.255 \pm 0.091923882$ & $32.75 \pm 1.48492424$ & $10 \pm 2$ & $3.9979 \pm 1.49949064$ \\
\hline
\end{tabular}

${ }^{\mathrm{a}}$ Accession no. is the Swiss-Prot accession; ${ }^{\mathrm{b}}$ unused protein score $>1.3$; ${ }^{\mathrm{c}} \%$ cov (95) means proteins total confidence $>95 \%$; ${ }^{\mathrm{d}}$ peptides $\geq 2$; eiTRAQ rate means the average of 115:114 in the two runs, and the rate $>1.5$.

sive than their parental cells. Consequently, we developed a subpopulation of XL-2 cells (XL-2sci) with enhanced metastatic competence.

Comparison of proliferation ability. The proliferation ability of XL-2 and XL-2sci cells was compared using growth curves and soft agar colony formation assay. The doubling time of XL-2 and XL-2sci cells was $31.92 \pm 2.73$ and $37.10 \pm 4.90 \mathrm{~h}$, respectively $(\mathrm{P}<0.05$, Fig. $7 \mathrm{~B})$, indicating that the proliferation rate of XL-2sci was significantly lower than that of XL-2. We achieved similar results as to the growth rate of s.c. tumors (Fig. 7C). In subsequent cell cycle analysis (Fig. 7D), data showed that $35.28 \%$ of XL-2 cells were in S phase, in contrast to $28.15 \%$ of XL-2sci cells. The number of XL-2sci cells in G2/M phase (18.79\%) was approximately two times higher than that of XL-2 cells, indicating a more proliferative phenotype in XL-2 compared with XL-2sci. In the soft agar colony formation assay, both cell lines produced colonies but had significantly different colony-formation ability (Fig. 7E-a). Both the number and size of XL-2 colonies increased when compared with those of the XL-2sci colonies (Fig. 7E-b). The two cell lines showed a significant difference $(\mathrm{P}<0.01)$ in the colony formation rate (Fig. 7E-c).

Differentially expressed proteins between XL-2sci and Xl-2. After one technical replicate, we respectively identified a total of 3347/3330 proteins (global FDR <1\%) using ProteinPilot 4.1.
Limited by the screening condition of unused protein score $>1.3$ and a number of peptides $\geq 2,2148 / 2373$ proteins were identified. There were 18 upregulated (iTRAQ ratio 115:114 >1.5) and 32 downregulated (iTRAQ ratio 115:114<0.67) proteins in XL-2sci cells, compared with XL-2 cells (Tables II and III).

GO analysis. GO analysis of the dysregulated proteins was performed via CapitalBio MAS 3.0. In terms of cellular component (CC), the differentially expressed proteins mainly focused on intracellular non-membrane-bound organelle, nonmembrane-bound organelle and cytosol; regarding molecular functions (MF), the dysregulated proteins mainly centered on protein binding, catalytic activity and nucleotide binding; as for biological processes (BP), the top three of the focused aspects are negative regulation of apoptosis, negative regulation of programmed cell death and negative regulation of cell death (Fig. 8).

\section{Discussion}

Well-characterized primary tumor cell lines can be invaluable tools for better understanding cancer biology (48) and exploring new treatment modalities. Nevertheless, many cell lines have lost their original biological characteristics during long-term culture in vitro $(49,50)$. Thus, the establishment of novel cell lines that reliably reflect clinical features is apparently needed. In general, the availability of newly established 
Table III. List of downregulated proteins.

\begin{tabular}{|c|c|c|c|c|c|}
\hline $\begin{array}{l}\text { Accession } \\
\text { no. }{ }^{\text {a }}\end{array}$ & $\begin{array}{l}\text { Protein } \\
\text { name }\end{array}$ & $\begin{array}{l}\text { Unused score } \\
(\text { mean } \pm \mathrm{SD})^{\mathrm{b}}\end{array}$ & $\begin{array}{c}\% \operatorname{cov}(95) \\
(\text { mean } \pm \text { SD) }\end{array}$ & $\begin{array}{l}\text { Peptides }(95 \%) \\
(\text { mean } \pm \mathrm{SD})^{\mathrm{d}}\end{array}$ & $\begin{array}{l}\text { iTRAQ rate } \\
(\text { mean } \pm S D)^{\mathrm{e}}\end{array}$ \\
\hline O14965 & AURKA & $4.415 \pm 2.057680733$ & $23.3 \pm 9.475230868$ & $3 \pm 1$ & $0.4295 \pm 0.107904495$ \\
\hline O43175 & SERA & $20.53 \pm 1.569777054$ & $32.65 \pm 4.030508653$ & $12 \pm 0$ & $0.31645 \pm 0.016475588$ \\
\hline O75643 & U520 & $62.62 \pm 2.884995667$ & $31.9 \pm 4.101219331$ & $41 \pm 7$ & $0.63135 \pm 0.032880465$ \\
\hline O95433 & AHSA1 & $20.09 \pm 1.329360749$ & $53.25 \pm 2.050609665$ & $16 \pm 3$ & $0.538 \pm 0.045537677$ \\
\hline P04818 & TYSY & $11.505 \pm 0.728319985$ & $30.2 \pm 3.818376618$ & $6.5 \pm 1$ & $0.42345 \pm 0.25335636$ \\
\hline P05120 & PAI2 & $23.4 \pm 0.353553391$ & $55.15 \pm 6.151828996$ & $14.5 \pm 1$ & $0.34675 \pm 0.047305444$ \\
\hline P09874 & PARP1 & $32.07 \pm 5.246732316$ & $32.9 \pm 0.282842712$ & $21.5 \pm 5$ & $0.4633 \pm 0.086974134$ \\
\hline P11216 & PYGB & $51.085 \pm 0.091923882$ & $52.1 \pm 1.414213562$ & $36 \pm 1$ & $0.52305 \pm 0.160866793$ \\
\hline P12277 & KCRB & $21.635 \pm 2.312239174$ & $46.05 \pm 7.283199846$ & $14 \pm 3$ & $0.24005 \pm 0.01251579$ \\
\hline P17931 & LEG3 & $16.34 \pm 5.628569978$ & $45.6 \pm 7.919595949$ & $16.5 \pm 1$ & $0.23475 \pm 0.095105862$ \\
\hline P18669 & PGAM1 & $31 \pm 5.868986284$ & $63.15 \pm 4.737615434$ & $22.5 \pm 2$ & $0.5916 \pm 0.080610173$ \\
\hline P23246 & SFPQ & $16.28 \pm 1.796051224$ & $29.95 \pm 0.494974747$ & $10.5 \pm 1$ & $0.421 \pm 0.02192031$ \\
\hline P23381 & SYWC & $19.145 \pm 2.877924599$ & $36.95 \pm 1.767766953$ & $14 \pm 0$ & $0.34825 \pm 0.065407377$ \\
\hline P23526 & SAHH & $28.685 \pm 0.16263456$ & $42.85 \pm 0.636396103$ & $22.5 \pm 1$ & $0.2939 \pm 0.01145513$ \\
\hline $\mathrm{P} 25815$ & S100P & $8.58 \pm 2.008183259$ & $44.75 \pm 3.74766594$ & $5 \pm 0$ & $0.4637 \pm 0.066185195$ \\
\hline P27695 & APEX1 & $18.65 \pm 0.707106781$ & $43.25 \pm 2.899137803$ & $13 \pm 0$ & $0.4232 \pm 0.03026417$ \\
\hline P43490 & NAMPT & $70.375 \pm 2.679934701$ & $73.65 \pm 2.474873734$ & $58 \pm 4$ & $0.60645 \pm 0.051265242$ \\
\hline P46821 & MAP1B & $57.255 \pm 6.130615793$ & $28.5 \pm 2.545584412$ & $34 \pm 3$ & $0.54755 \pm 0.109813683$ \\
\hline P62805 & $\mathrm{H} 4$ & $19.71 \pm 2.870853532$ & $60.2 \pm 1.414213562$ & $18.5 \pm 2$ & $0.037 \pm 0.010040916$ \\
\hline Q05639 & $\mathrm{EF} 1 \mathrm{~A} 2$ & $10.905 \pm 3.712310601$ & $59.55 \pm 2.899137803$ & $33.5 \pm 1$ & $0.2535 \pm 0.159664711$ \\
\hline Q14432 & PDE3A & $3.575 \pm 0.827314934$ & $10.15 \pm 1.767766953$ & $2 \pm 0$ & $0.61095 \pm 0.004030509$ \\
\hline Q15020 & SART3 & $11.395 \pm 1.803122292$ & $20.95 \pm 2.333452378$ & $7 \pm 1$ & $0.44965 \pm 0.040941483$ \\
\hline Q16555 & DPYL2 & $46.505 \pm 6.130615793$ & $58.4 \pm 0$ & $31.5 \pm 2$ & $0.48235 \pm 0.124238661$ \\
\hline Q6EMK4 & VASN & $3.53 \pm 0.381837662$ & $10.65 \pm 5.161879503$ & $2.5 \pm 1$ & $0.47635 \pm 0.110662211$ \\
\hline Q6FI13 & $\mathrm{H} 2 \mathrm{~A} 2 \mathrm{~A}$ & $2 \pm 0$ & $51.9 \pm 3.818376618$ & $12.5 \pm 1$ & $0.3077 \pm 0.09277241$ \\
\hline Q9NR30 & DDX21 & $29.19 \pm 0.537401154$ & $37.65 \pm 8.838834765$ & $17.5 \pm 1$ & $0.38045 \pm 0.019869701$ \\
\hline Q9Y2J2-2 & E41L3 & $12.555 \pm 2.453660531$ & $21.35 \pm 0.494974747$ & $8.5 \pm 1$ & $0.2993 \pm 0.090226825$ \\
\hline D6RD18 & D6RD18 & $10.985 \pm 0.784888527$ & $36.9 \pm 3.252691193$ & $8 \pm 1$ & $0.42375 \pm 0.071347074$ \\
\hline F8W1S7 & F8W1S7 & $35.69 \pm 2.771858582$ & $70.75 \pm 1.060660172$ & $41 \pm 6$ & $0.55985 \pm 0.15125014$ \\
\hline F8W6L6 & F8W6L6 & $37.705 \pm 8.20950973$ & $32.5 \pm 1.555634919$ & $32 \pm 10$ & $0.2693 \pm 0.012303658$ \\
\hline J3QSV6 & J3QSV6 & $8.94 \pm 0.721248917$ & $29.05 \pm 0.636396103$ & $4.5 \pm 1$ & $0.46375 \pm 0.236527218$ \\
\hline Q4JM47 & Q4JM47 & $11.21 \pm 3.012274888$ & $44.65 \pm 2.192031022$ & $8 \pm 0$ & $0.1281 \pm 0.108894444$ \\
\hline
\end{tabular}

${ }^{\mathrm{a}-\mathrm{e}} \mathrm{Same}$ as in Table II.

lung cancer cell lines is relatively more limited compared with other types of epithelia-originating cell lines. Not direct ascites fluid incubation, but gradient centrifugation was introduced in our study. The advances in cell culture methods enabled us to develop a permanently growing lung cancer cell line.

Through cellular and histological techniques, XL-2 was finally identified as a lung adenocarcinoma cell line. The structural and numerical aberrations in karyotype analysis illustrated its genomic abnormalities. Drug trail showed that it was sensitive to docetaxel and resistant to doxorubicin, which might be attributed to the patient's multiple chemotherapy with doxorubicin. Hence, XL-2 cell line may serve as a cell line model of drug resistance for identifying mechanisms involved in the resistance to doxorubicin. To sum up, this newly isolated cell line should provide a beneficial addition to the cell lines currently available for investigating the biological characteristics of lung cancer.

Although metastasis is the foremost cause of lung cancer recurrence and mortality, we have limited access to the mechanisms. Searching for metastasis-associated genes and proteins will contribute greatly to the inhibition of tumor development and progression. This spontaneous metastatic model derived from s.c. injection provided us with a new cell line with much increased metastatic properties, XL-2sci. Its enhanced meta- 
A

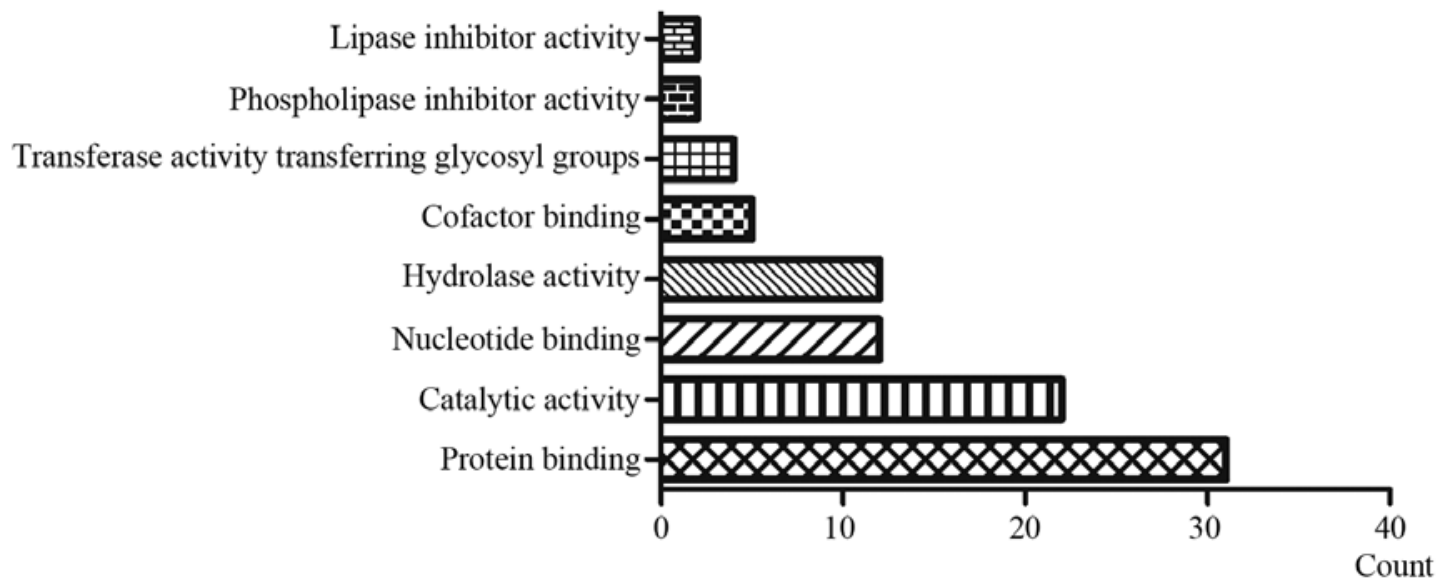

B

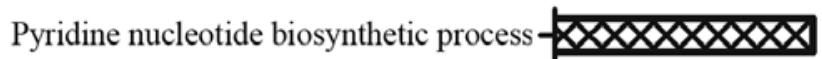

Cellular carbohydrate catabolic process

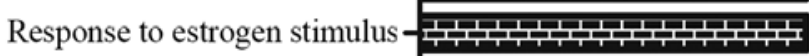

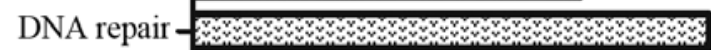

Anti-apoptosis-IIIIIIIIIIIIIIIIIIIII

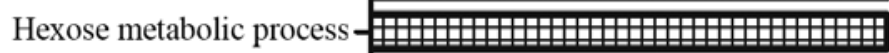

Glucose metabolic process -

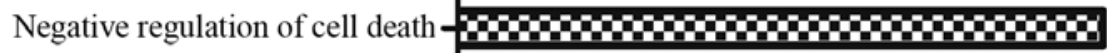

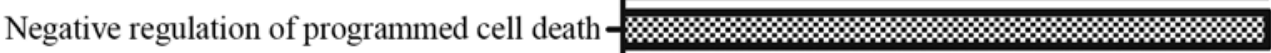

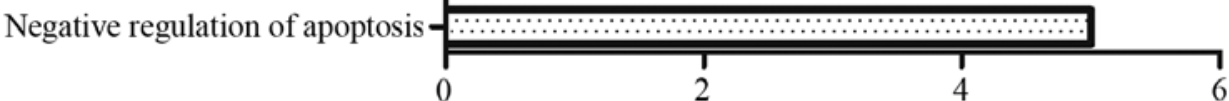

Count

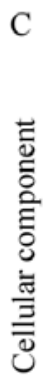

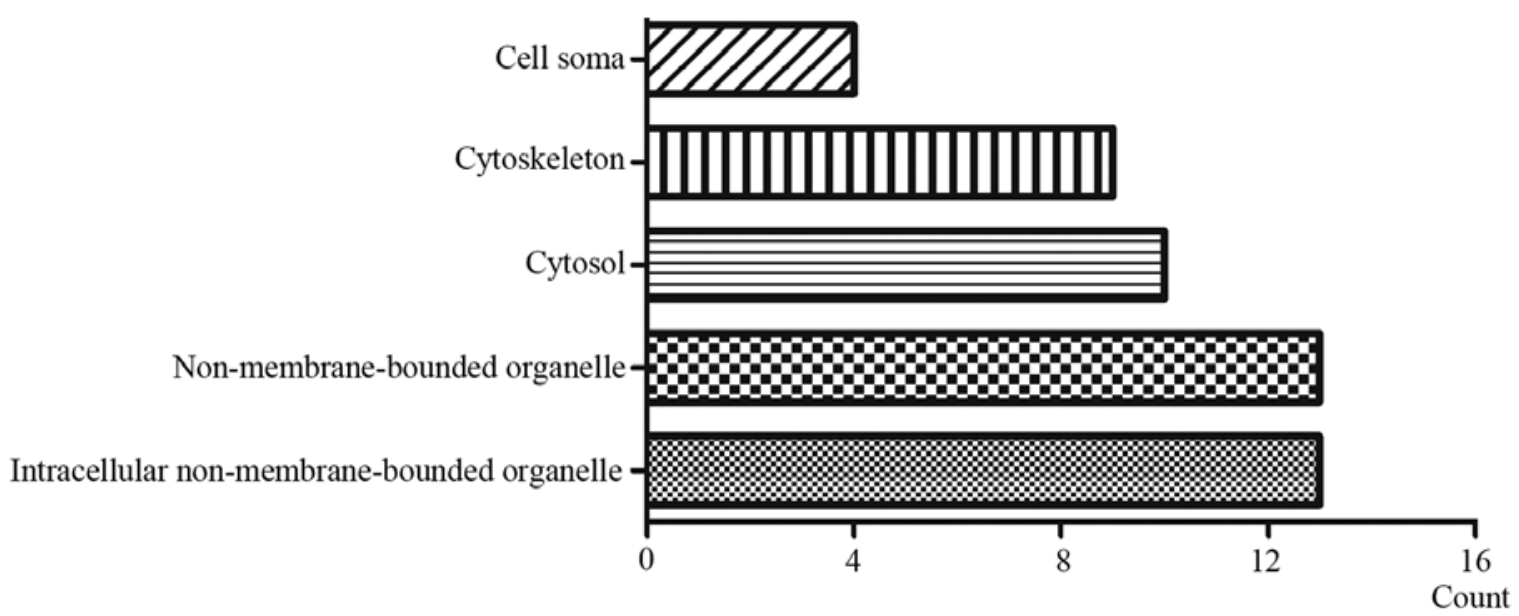

Figure 8. The GO analysis of the 50 dysregulated proteins. (A) Histograms were used to analyze the counts for molecular function analysis. (B) Histograms were used to analyze the counts for biological process analysis. (C) Histograms were used to analyze the counts for cellular component analysis of the 50 dysregulated proteins by CapitalBio MAS 3.0.

static capacity versus XL-2 was identified by optical imaging, micro-CT scanning in vivo and Transwell assays in vitro. Besides, by means of ITRAQ labeled proteomics profiling study, we also found 50 dysregulated proteins in XL-2sci, some of which played an important role in tumor metastasis. For example, FSCN1 has been reported to be relevant with NSCLC metastasis, and G3V1S6 was said to be involved in the distant metastasis of breast cancer (51), gastric cancer (52) plus liver cancer (53). In addition, NDRG1 was connected with colorectal cancer and liver cancer, whereas, it was highly expressed in lung cancer. Hence, in a subsequent study, we can choose some of these metastasis-associated proteins having been reported in other types of tumors to further explore their role in lung cancer metastasis. 
Proliferation ability of the two cell lines were also evaluated in our study. Not only the doubling time and soft agar colony formation assays in vitro but also the growth rate of s.c. tumors in vivo suggested that XL-2sci cell line had a decreased proliferation ability, indicating its enhanced invasion and metastatic activity was not facilitated by a faster growth rate. An inverse correlation between proliferation and metastasis was demonstrated in our study, which was consistent with previous reports $(31,54)$.

In conclusion, we triumphantly established a lung adenocarcinoma cell line (XL-2) from clinical specimens and characterized it at cellular and histological levels. By means of XL-2 cells, we developed a metastatic model via s.c. injection and harvested a novel cell line with enhanced metastatic competence (XL-2sci). Retaining the clinical features of original tumor, this metastatic model will offer a reliable platform for in-depth investigation of lung cancer.

\section{Acknowledgements}

This study was supported by Natural Science Foundation of China (81472176), Shanghai Science and Technology Developing Program (13140900502), State Key Laboratory of Oncogenes and Related Genes Research Fund (91-14-15). We would like to thank Li-Xing Zhang, Li-Xia Wu and Yu Zhang for their kind suggestions and excellent technical assistance. We also thank the Nature Publishing Group Language Editing for revising the English used in this manuscript.

\section{References}

1. Siegel R, Naishadham D and Jemal A: Cancer statistics, 2012. CA Cancer J Clin 62: 10-29, 2012.

2. Hanahan D and Weinberg RA: The hallmarks of cancer. Cell 100: 57-70, 2000.

3. Crinò L, Weder W, van Meerbeeck $\mathrm{J}$ and Felip E; ESMO Guidelines Working Group: Early stage and locally advanced (non-metastatic) non-small-cell lung cancer: ESMO Clinical Practice Guidelines for diagnosis, treatment and follow-up. Ann Oncol 21 (Suppl 5): V103-V115, 2010.

4. Sekhon HS, London CA, Sekhon M, Iversen PL and Devi GR: c-MYC antisense phosphosphorodiamidate morpholino oligomer inhibits lung metastasis in a murine tumor model. Lung Cancer 60: $347-354,2008$

5. Fork MA, Murua Escobar H, Soller JT, Sterenczak KA, Willenbrock S, Winkler S, Dorsch M, Reimann-Berg N, Hedrich HJ, Bullerdiek J, et al: Establishing an in vivo model of canine prostate carcinoma using the new cell line CT1258. BMC Cancer 8: 240, 2008.

6. Capellá G, Farré L, Villanueva A, Reyes G, García C, Tarafa G and Lluís F: Orthotopic models of human pancreatic cancer. Ann NY Acad Sci 880: 103-109, 1999.

7. Talmadge JE, Singh RK, Fidler IJ and Raz A: Murine models to evaluate novel and conventional therapeutic strategies for cancer. Am J Pathol 170: 793-804, 2007.

8. Minn AJ, Gupta GP, Siegel PM, Bos PD, Shu W, Giri DD, Viale A, Olshen AB, Gerald WL and Massagué J: Genes that mediate breast cancer metastasis to lung. Nature 436: 518-524, 2005.

9. Daniel VC, Marchionni L, Hierman JS, Rhodes JT, Devereux WL, Rudin CM, Yung R, Parmigiani G, Dorsch M, Peacock CD, et al: A primary xenograft model of small-cell lung cancer reveals irreversible changes in gene expression imposed by culture in vitro. Cancer Res 69: 3364-3373, 2009.

10. Frese KK and Tuveson DA: Maximizing mouse cancer models. Nat Rev Cancer 7: 645-658, 2007.

11. Voskoglou-Nomikos T, Pater JL and Seymour L: Clinical predictive value of the in vitro cell line, human xenograft, and mouse allograft preclinical cancer models. Clin Cancer Res 9: 4227-4239, 2003.
12. Hammer S, Sommer A, Fichtner I, Becker M, Rolff J, Merk J, Klar U and Hoffmann J: Comparative profiling of the novel epothilone, sagopilone, in xenografts derived from primary non-small cell lung cancer. Clin Cancer Res 16: 1452-1465, 2010.

13. Masui O, White NM, DeSouza LV, Krakovska O, Matta A, Metias S, Khalil B, Romaschin AD, Honey RJ, Stewart R, et al: Quantitative proteomic analysis in metastatic renal cell carcinoma reveals a unique set of proteins with potential prognostic significance. Mol Cell Proteomics 12: 132-144, 2013.

14. Hou Q, Tan HT, Lim KH, Lim TK, Khoo A, Tan IB, Yeoh KG and Chung MC: Identification and functional validation of caldesmon as a potential gastric cancer metastasis-associated protein. J Proteome Res 12: 980-990, 2013.

15. Qin X, Chen Q, Sun C, Wang C, Peng Q, Xie L, Liu Y and Li S: High-throughput screening of tumor metastatic-related differential glycoprotein in hepatocellular carcinoma by iTRAQ combines lectin-related techniques. Med Oncol 30: 420, 2013.

16. Yu T, Li J, Yan M, Liu L, Lin H, Zhao F, Sun L, Zhang Y, Cui Y, Zhang F, et al: MicroRNA-193a-3p and -5p suppress the metastasis of human non-small-cell lung cancer by downregulating the ERBB4/PIK3R3/mTOR/S6K2 signaling pathway. Oncogene 34: 413-423, 2015.

17. Lin HC, Zhang FL, Geng Q, Yu T, Cui YQ, Liu XH, Li J, Yan MX, Liu L, He XH, et al: Quantitative proteomic analysis identifies CPNE3 as a novel metastasis-promoting gene in NSCLC. J Proteome Res 12: 3423-3433, 2013.

18. Dunkley PR, Jarvie PE and Robinson PJ: A rapid Percoll gradient procedure for preparation of synaptosomes. Nat Protoc 3: 1718-1728, 2008.

19. Zhao Q, Feng Y, Jia X, Yin L, Zheng Y, Ouyang D, Zhou H and Zhang L: Proteome analysis of hepatic non-parenchymal cells of immune liver fibrosis rats. Sci China Life Sci 57: 303-314, 2014.

20. Bartnitzke S, Motzko H, Caselitz J, Kornberg M, Bullerdiek J and Schloot W: A recurrent marker chromosome involving chromosome 1 in two mammary tumors of the dog. Cytogenet Cell Genet 60: 135-137, 1992.

21. Chambers JK, Uchida K, Ise K and Nakayama H: Cystic rete ovarii and uterine tube adenoma in a rabbit. J Vet Med Sci 76: 909-912, 2014

22. Cousins FL, Murray A, Esnal A, Gibson DA, Critchley HO and Saunders PT: Evidence from a mouse model that epithelial cell migration and mesenchymal-epithelial transition contribute to rapid restoration of uterine tissue integrity during menstruation. PLoS One 9: e86378, 2014.

23. Kamalidehghan B, Houshmand M, Kamalidehghan F, Jafarzadeh N, Azari S, Akmal SN and Rosli R: Establishment and characterization of two human breast carcinoma cell lines by spontaneous immortalization: Discordance between estrogen, progesterone and HER2/neu receptors of breast carcinoma tissues with derived cell lines. Cancer Cell Int 12: 43, 2012.

24. Sozo F, Wallace MJ, Hanna MR, Flecknoe SJ, Cock ML, Maritz GS, Harding R and Hooper SB: Alveolar epithelial cell differentiation and surfactant protein expression after mild preterm birth in sheep. Pediatr Res 59: 151-156, 2006.

25. Woodcock-Mitchell J, Mitchell JJ, Reynolds SE, Leslie KO and Low RB: Alveolar epithelial cell keratin expression during lung development. Am J Respir Cell Mol Biol 2: 503-514, 1990.

26. Ito Y, Ahmad A, Kewley E and Mason RJ: Hypoxia-inducible factor regulates expression of surfactant protein in alveolar type II cells in vitro. Am J Respir Cell Mol Biol 45: 938-945, 2011.

27. Ito $\mathrm{Y}$ and Mason RJ: The effect of interleukin-13 (IL-13) and interferon- $\gamma($ IFN- $\gamma)$ on expression of surfactant proteins in adult human alveolar type II cells in vitro. Respir Res 11: 157, 2010.

28. Peng T, Zhang P, Liu J, Nguyen T, Bolshakov S, Belousov R, Young ED, Wang X, Brewer K, López-Terrada DH, et al: An experimental model for the study of well-differentiated and dedifferentiated liposarcoma; deregulation of targetable tyrosine kinase receptors. Lab Invest 91: 392-403, 2011.

29. Lv S, Tang Z, Li M, Lin J, Song W, Liu H, Huang Y, Zhang Y and Chen X: Co-delivery of doxorubicin and paclitaxel by PEG-polypeptide nanovehicle for the treatment of non-small cell lung cancer. Biomaterials 35: 6118-6129, 2014.

30. Munoz R, Man S, Shaked Y, Lee CR, Wong J, Francia G and Kerbel RS: Highly efficacious nontoxic preclinical treatment for advanced metastatic breast cancer using combination oral UFT-cyclophosphamide metronomic chemotherapy. Cancer Res 66: 3386-3391, 2006. 
31. Jia D, Yan M, Wang X, Hao X, Liang L, Liu L, Kong H, He X, Li J and Yao M: Development of a highly metastatic model that reveals a crucial role of fibronectin in lung cancer cell migration and invasion. BMC Cancer 10: 364, 2010.

32. Caceres G, Zhu XY, Jiao JA, Zankina R, Aller A and Andreotti P: Imaging of luciferase and GFP-transfected human tumours in nude mice. Luminescence 18: 218-223, 2003.

33. Ciana P, Brena A, Sparaciari P, Bonetti E, Di Lorenzo D and Maggi A: Estrogenic activities in rodent estrogen-free diets. Endocrinology 146: 5144-5150, 2005.

34. Takahashi M, Furihata M, Akimitsu N, Watanabe M, Kaul S, Yumoto $\mathrm{N}$ and Okada T: A highly bone marrow metastatic murine breast cancer model established through in vivo selection exhibits enhanced anchorage-independent growth and cell migration mediated by ICAM-1. Clin Exp Metastasis 25: 517-529, 2008.

35. Zhang F, Lin H, Gu A, Li J, Liu L, Yu T, Cui Y, Deng W, Yan M, Li J, et al: SWATH ${ }^{\mathrm{TM}}$ - and iTRAQ-based quantitative proteomic analyses reveal an overexpression and biological relevance of CD109 in advanced NSCLC. J Proteomics 102: 125-136, 2014.

36. Conway AE, Lindgren A, Galic Z, Pyle AD, Wu H, Zack JA, Pelligrini M, Teitell MA and Clark AT: A self-renewal program controls the expansion of genetically unstable cancer stem cells in pluripotent stem cell-derived tumors. Stem Cells 27: 18-28, 2009.

37. Mimura T, Ito A, Sakuma T, Ohbayashi C, Yoshimura M, Tsubota N, Okita Y and Okada M: Novel marker D2-40, combined with calretinin, CEA, and TTF-1: An optimal set of immunodiagnostic markers for pleural mesothelioma. Cancer 109: 933-938, 2007.

38. Ordóñez NG: The immunohistochemical diagnosis of mesothelioma: A comparative study of epithelioid mesothelioma and lung adenocarcinoma. Am J Surg Pathol 27: 1031-1051, 2003.

39. Yokouchi H, Yamazaki K, Asahina H, Shigemura M, Moriyama T, Takaoka K, Moriya J, Itoh T, Kinoshita I, Dosaka-Akita H, et al: Establishment and characterization of amylase-producing lung adenocarcinoma cell line, IMEC-2. Anticancer Res 26B: 2821-2827, 2006

40. Moldvay J, Jackel M, Bogos K, Soltész I, Agócs L, Kovács G and Schaff Z: The role of TTF-1 in differentiating primary and metastatic lung adenocarcinomas. Pathol Oncol Res 10: 85-88, 2004

41. Bejarano PA, Baughman RP, Biddinger PW, Miller MA, FenoglioPreiser C, al-Kafaji B, Di Lauro R and Whitsett JA: Surfactant proteins and thyroid transcription factor-1 in pulmonary and breast carcinomas. Mod Pathol 9: 445-452, 1996.

42. Minotti G, Menna P, Salvatorelli E, Cairo G and Gianni L: Anthracyclines: Molecular advances and pharmacologic developments in antitumor activity and cardiotoxicity. Pharmacol Rev 56: $185-229,2004$
43. Tacar O, Sriamornsak P and Dass CR: Doxorubicin: An update on anticancer molecular action, toxicity and novel drug delivery systems. J Pharm Pharmacol 65: 157-170, 2013.

44. Ramalingam SS and Khuri FR: The role of the taxanes in the treatment of older patients with advanced stage non-small cell lung cancer. Oncologist 14: 412-424, 2009.

45. Pan B, Chen D, Huang J, Wang R, Feng B, Song H and Chen L: HMGB1-mediated autophagy promotes docetaxel resistance in human lung adenocarcinoma. Mol Cancer 13: 165, 2014.

46. Wang R, Huang J, Feng B, De W and Chen L: Identification of ING4 (inhibitor of growth 4) as a modulator of docetaxel sensitivity in human lung adenocarcinoma. Mol Med 18: 874-886, 2012.

47. Miller VA and Kris MG: Docetaxel (Taxotere) as a single agent and in combination chemotherapy for the treatment of patients with advanced non-small cell lung cancer. Semin Oncol 27 (Suppl 3): 3-10, 2000.

48. Ku JL, Yoon KA, Kim IJ, Kim WH, Jang JY, Suh KS, Kim SW, Park YH, Hwang JH, Yoon YB, et al: Establishment and characterisation of six human biliary tract cancer cell lines. Br J Cancer 87: 187-193, 2002.

49. Burdall SE, Hanby AM, Lansdown MR and Speirs V: Breast cancer cell lines: Friend or foe? Breast Cancer Res 5: 89-95, 2003.

50. Osborne CK, Hobbs K and Trent JM: Biological differences among MCF-7 human breast cancer cell lines from different laboratories. Breast Cancer Res Treat 9: 111-121, 1987.

51. Gill DJ, Tham KM, Chia J, Wang SC, Steentoft C, Clausen H, Bard-Chapeau EA and Bard FA: Initiation of GalNAc-type $\mathrm{O}$-glycosylation in the endoplasmic reticulum promotes cancer cell invasiveness. Proc Natl Acad Sci USA 110: E3152-E3161, 2013.

52. Hua D, Shen L, Xu L, Jiang Z, Zhou Y, Yue A, Zou S, Cheng Z and $\mathrm{Wu}$ S: Polypeptide N-acetylgalactosaminyltransferase 2 regulates cellular metastasis-associated behavior in gastric cancer. Int J Mol Med 30: 1267-1274, 2012.

53. Wu YM, Liu CH, Hu RH, Huang MJ, Lee JJ, Chen CH, Huang J, Lai HS, Lee PH, Hsu WM, et al: Mucin glycosylating enzyme GALNT2 regulates the malignant character of hepatocellular carcinoma by modifying the EGF receptor. Cancer Res 71: 7270-7279, 2011

54. Zhu LF, Hu Y, Yang CC, Xu XH, Ning TY, Wang ZL, Ye JH and Liu LK: Snail overexpression induces an epithelial to mesenchymal transition and cancer stem cell-like properties in SCC9 cells. Lab Invest 92: 744-752, 2012. 